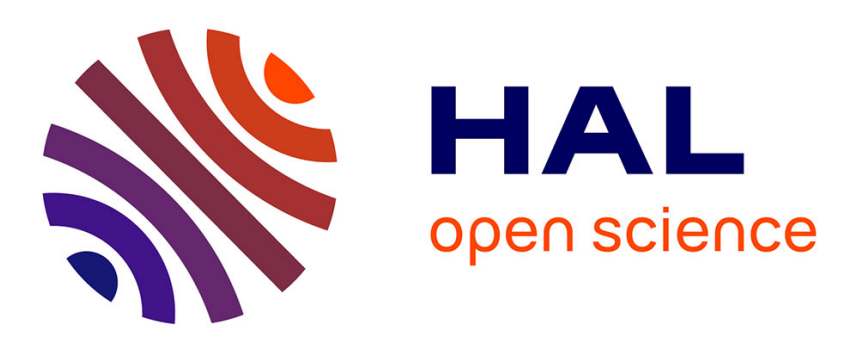

\title{
Alteration of human macrophage phenotypes by the anti-fibrotic drug nintedanib
}

Nessrine Bellamri, Claudie Morzadec, Audrey Joannes, Valérie Lecureur, Lutz Wollin, Stéphane Jouneau, Laurent Vernhet

\section{- To cite this version:}

Nessrine Bellamri, Claudie Morzadec, Audrey Joannes, Valérie Lecureur, Lutz Wollin, et al.. Alteration of human macrophage phenotypes by the anti-fibrotic drug nintedanib. International Immunopharmacology, 2019, 72, pp.112-123. 10.1016/j.intimp.2019.03.061 . hal-02119173

\section{HAL Id: hal-02119173 \\ https://hal-univ-rennes1.archives-ouvertes.fr/hal-02119173}

Submitted on 22 Oct 2021

HAL is a multi-disciplinary open access archive for the deposit and dissemination of scientific research documents, whether they are published or not. The documents may come from teaching and research institutions in France or abroad, or from public or private research centers.
L'archive ouverte pluridisciplinaire HAL, est destinée au dépôt et à la diffusion de documents scientifiques de niveau recherche, publiés ou non, émanant des établissements d'enseignement et de recherche français ou étrangers, des laboratoires publics ou privés.

\section{(ㄷ)(1) $\$$}

Distributed under a Creative Commons Attribution - NonCommerciall 4.0 International 


\section{Alteration of human macrophage phenotypes by the anti-fibrotic drug nintedanib}

Nessrine Bellamri ${ }^{1}$, Claudie Morzadec ${ }^{1}$, Audrey Joannes ${ }^{1}$, Valérie Lecureur ${ }^{1}$, Lutz Wollin², Stéphane Jouneau ${ }^{1,3^{*}}$ and Laurent Vernhet ${ }^{1 * \#}$

${ }^{1}$ Univ Rennes, CHU Rennes, Inserm, EHESP, Irset (Institut de recherche en santé, environnement et travail) - UMR_S 1085, F-35000 Rennes, France

${ }^{2}$ Boehringer Ingelheim Pharma GmbH \& Co, KG, Biberach an der Riss, Germany

${ }^{3}$ Department of Respiratory Diseases, Competence Centre for Rare Pulmonary Disease, Rennes University Hospital, 35033, Rennes, France

*Stéphane Jouneau and Laurent Vernhet contributed equally

\#Corresponding author: Laurent VERNHET, Univ Rennes, CHU Rennes, Inserm, EHESP, Irset (Institut de recherche en santé, environnement et travail) - UMR_S 1085, F-35000 Rennes, France. Phone: 33-2-23-23-48-07; Fax: 33-2-23-23-47-94. Email: laurent.vernhet@univ-rennes1.fr

Abbreviations: NTD: nintedanib, CSF1: colony-stimulating factor 1, CSF1R: colonystimulating factor 1 receptor, IPF: idiopathic pulmonary fibrosis, VEGF: vascular endothelial growth factor, bFGF: basic fibroblast growth factor, PDGF: platelet-derived growth factor, PI3K: phosphatidylinositol 3-kinase, MAPK: mitogen-activated protein kinases, IL: interleukin, CCL: C-C motif chemokine ligand, INF: interferon- $\gamma$, 


\section{Abstract}

The tyrosine kinase inhibitor, Nintedanib (NTD), has been approved for the treatment of idiopathic pulmonary fibrosis (IPF). In cell-free systems, NTD was recently shown to inhibit kinase activity of the human recombinant colony-stimulating factor 1 (CSF1) receptor (CSF1R) which mediates major functions of pulmonary macrophages. In the present study, we have investigated the effects of NTD on the phenotype of human monocyte-derived macrophages controlled by CSF1 in order to identify its anti-inflammatory properties via CSF1R inhibition. NTD $(0.01$ to $1 \mu \mathrm{M})$ prevented the CSF1-induced phosphorylation of CSF1R and activation of the downstream signaling pathways. NTD, like the CSF1R inhibitor GW2580, significantly decreased the adhesion of macrophages and production of the chemokine ligand (CCL) 2. NTD also altered the polarization of macrophages to classical M1 and alternative $\mathrm{M} 2 \mathrm{a}$ macrophages. It reduced the secretion of several pro-inflammatory and/or pro-fibrotic cytokines (IL-1 $\beta$, IL-8, IL-10 and CXCL13) by M1 macrophages but did not prevent the expression of M1 markers. While NTD (50-200 nM) partially blocked the synthesis of M2a markers (CD11b, CD200R, CD206, and CD209), it did not reduce synthesis of the M2a pro-fibrotic cytokines CCL22 and PDGF-BB, and increased CCL18 release when used at its highest concentration $(1 \mu \mathrm{M})$. The effects of NTD on macrophage polarization only was partially mimicked by GW2580, suggesting that the drug inhibits other molecules in addition to CSF1R. In conclusion, NTD alters the CSF1-controlled phenotype of human macrophages mainly by blocking the activation of CSF1R that thus constitutes a new molecular target of NTD, at least in vitro.

Keywords: Nintedanib, idiopathic pulmonary fibrosis, inflammation, macrophages, CSF1R, polarization 


\section{Introduction}

The anti-fibrotic drug nintedanib (NTD) has been approved for the management of idiopathic pulmonary fibrosis (IPF) [1]. It reduces the annual decrease in forced vital capacity and acute exacerbations in patients suffering from this progressive, irreversible lung disease [2]. This tyrosine kinase inhibitor blocks the ATP-binding sites within the kinase domains of vascular endothelial growth factor (VEGF), basic fibroblast growth factor (bFGF) and platelet-derived growth factor (PDGF) receptors [3]. It also inhibits the PDGF, VEGF or bFGF-dependent proliferation of fibroblasts isolated from the lungs of IPF patients $[4,5]$.

In addition, several studies have shown that NTD prevents the development of inflammatory processes during fibrosis in murine models of lung, liver, renal and skin fibrosis $[4,6-8]$. It reduces the infiltration of lymphocytes and neutrophils induced by silica or bleomycin in lungs [4] and it decreases the infiltration of macrophages induced by unilateral ureteral obstruction in kidney [7]. Moreover, NTD markedly prevents the expression of major pro-inflammatory and pro-fibrotic cytokines, such as tumor necrosis factor- $\alpha$ (TNF- $\alpha$ ), interleukin-(IL-)1 1 , IL-6 or chemokine ligand (CCL) 2 (CCL2), in fibrotic liver, lung and kidneys.

A recent screening of a wide range of kinases in cell-free systems demonstrated that low concentrations ( $\mathrm{IC}_{50}=5 \pm 2 \mathrm{nM}$ ) of NTD inhibit the kinase activity of human recombinant colony-stimulating factor 1 (CSF1) receptor (CSF1R) [9]. This receptor, activated by CSF1 (also called macrophage colony-stimulating factor) and IL-34, is mainly expressed in myeloid cells [10]. The CSF1R/CSF1 complex plays major roles in innate immunity and bone remodeling by osteoclasts, but it also possesses an oncogenic potential due to its aberrant expression in several human tumors cells [11]. Overall, CSF1 is a main hematopoietic growth factor for cells of the monocyte lineage. M-CSF bound to CSF1R activates several intracellular signal pathways, such as phosphatyidylinositol 3-kinase (PI3K), inducing the differentiation of monocytes into mature macrophages and promoting their adhesion, spreading and motility [10]. CSF1 also stimulates the production of the chemokine CCL2 by 
macrophages, which contributes significantly to lung fibrosis [12]. The capacity of NTD to inhibit CSF1R activation and downstream signals in vitro has never been investigated although CSF1-activated macrophages are important in pulmonary inflammation and fibrosis $[12,13]$. Indeed, the pulmonary tissues of $\mathrm{CSF}^{-/-}$and $\mathrm{CCL}^{--}$mice have less macrophage infiltration, collagen deposition and fibrosis in response to bleomycin than do those of wildtype mice [12]. The accumulation of lung macrophages and subsequent pulmonary fibrosis suffered by mice after thorax irradiation is blocked by inhibiting CSF1R [13]. These pulmonary macrophages may differentiate from circulating monocytes that infiltrate the lungs in response to pro-fibrotic stimuli [14]. In fact, the genetic deletion of monocyte-derived macrophages or the depletion of circulating monocytes by liposomal clodronate potently reduces the number of alveolar macrophages and the development of lung fibrosis in different murine models [15,16]. In humans, the bronchoalveolar lavage fluids of patients with IPF contain higher concentrations of CSF1 and CCL2 than do those of healthy controls [12]. CSF1 specifically stimulates the production of the CD163 marker in human monocytederived macrophages [17], and above-normal numbers of CD163-positive macrophages have been detected in fibrotic areas of the lungs of IPF and irradiated patients [12,13]. Altogether, these results suggest that NTD may exert anti-inflammatory and anti-fibrotic effects in the lungs by altering the phenotype of human CSF1-dependent macrophages through CSF1R inhibition.

We have investigated this relationship to obtain a clearer picture of the anti-inflammatory effects of the drug on human macrophages. To this goal, we exposed primary cultures of human monocyte-derived macrophages, differentiated with CSF1, to nanomolar concentrations of NTD that were in the range of the blood plasma drug concentrations measured in patients with IPF after a steady-state standard dosing of two times $150 \mathrm{mg}$ per day [18]. In these patients, the highest NTD blood concentrations were about 70 nM. Our results demonstrate that NTD $(10-1000 \mathrm{nM})$ inhibited the phosphorylation of CSF1R and the downstream signaling pathways induced by CSF1 in human macrophages. At 200-1000 nM, 
NTD reduced the adhesion of CSF1 macrophages, without inducing cytotoxicity, and repressed the expression of CCL2. In addition, NTD (200-1000 nM) altered the polarization of human macrophages by decreasing the production of pro-fibrotic cytokines and the membrane expression of markers in M1 and M2a macrophages, respectively. 


\section{Materials and Methods}

\subsection{Chemicals and reagents}

NTD [BIBF-1120, methyl (3Z)-3-[(\{4-[N-methyl-2-(4-methylpiperazin-1yl)acetamido]phenyl\}amino)(phenyl)methylidene]-2-oxo-2,3-dihydro-1H-indole-6-carboxylate ethane sulfonate salt] was provided by Boehringer Ingelheim Pharma GmbH (Biberach, Germany). CSF1 was purchased from Miltenyi Biotec (Paris, France). Lipopolysaccharide (LPS) (Escherichia coli O55:B5), the PI3K inhibitor LY294002, and GW2580, an ATPcompetitive inhibitor of CSF1R, were from Sigma-Aldrich (Saint-Quentin Fallavier, France). Interferon- $\gamma$ (IFN), IL-4 and IL-13 were obtained from PeproTech (Neuilly-sur-seine, France). Crystalline silica (DQ12, $100 \mu \mathrm{g} / \mathrm{ml}$ ) was from DMT GMBH, Germany. Primary antibodies (Ab) against phospho-CSF1R (Tyr723), CSF1R, phospho-AKT (Ser473), AKT, phosphop44/42 extracellular regulated kinases (ERK) (Thr202/Tyr204), ERK, and GAPDH were from Cell Signaling Technology (Ozyme, Montigny-le-Bretonneux, France).

\subsection{Cell culture and treatments}

Human macrophages were differentiated from peripheral human blood monocytes. Each donor gave his/her written consent for the use of blood samples for research (Etablissement Français du Sang). Briefly, peripheral blood mononuclear cells from healthy donors were first isolated by a Ficoll (reference CMSMSL01, Eurobio, Les Ulis, France) gradient centrifugation, and then monocytes were selected by a $2 \mathrm{~h}$ adhesion step. These cells were cultured for 6-7 days in RPMI 1640 medium GlutaMAX (Gibco, Life technologies), containing $10 \%$ heat-inactivated fetal bovine serum (FBS), $2 \mathrm{mM} \mathrm{L-glutamine,} 20 \mathrm{IU} / \mathrm{mL}$ penicillin, $20 \mu \mathrm{g} / \mathrm{mL}$ streptomycin and $50 \mathrm{ng} / \mathrm{ml} \mathrm{CSF1}$ to obtain mature M0 macrophages [19]. These M0 macrophages were cultured in complete RPMI-1640 medium with or without $10 \mathrm{ng} / \mathrm{ml}$ CSF1. They were polarized by culturing them for $24 \mathrm{~h}$ in RPMI medium containing $5 \% \mathrm{FBS}$, $10 \mathrm{ng} / \mathrm{ml} \mathrm{CSF1}$ and appropriate cytokines, as follows: incubation with $20 \mathrm{ng} / \mathrm{ml}$ LPS +20 $\mathrm{ng} / \mathrm{ml}$ IFN polarized them into classical M1 macrophages while incubation with $20 \mathrm{ng} / \mathrm{ml} \mathrm{IL-4}$ 
+ 20 ng/ml IL-13 resulted in alternative M2a macrophages [20]. For each biological endpoint assessed in the present study, all biological replicates were performed with macrophages differentiated from blood monocytes collected from different donors. Overall, we isolated peripheral blood monocytes from 36 different donors.

For treatments, the M0 macrophages were incubated with NTD $(0.1$ to $1 \mu \mathrm{M})$ for $2 \mathrm{~h}$ and then stimulated with CSF1 or polarized to M1 or M2a macrophages. In some experiments, M0 macrophages were first treated with LPS/IFN for $4 \mathrm{~h}$ and then cultured with $100 \mu \mathrm{g} / \mathrm{ml}$ silica for $16 \mathrm{~h}$ to induce IL-1 $\beta$ secretion and inflammasome activity. NTD remained in the culture medium during polarization. A $1 \mathrm{mM}$ stock solution of NTD was prepared by dissolving it in water at $50^{\circ} \mathrm{C}$.

\subsection{Cell viability}

Cell viability was measured by flow cytometry using the FITC Annexin-V Apoptosis Detection Kit I (BD Biosciences, Le Pont de Claix, France) according to the manufacturer's instructions. Briefly, adherent and floating cells were harvested and centrifuged at $600 \mathrm{~g}$ for 5 $\min$ at room temperature. Macrophages were detached with Accutase ${ }^{\mathrm{TM}}$ (Biolegends, London, UK), washed with cold PBS and suspended in binding buffer (PBS, 2 \% FBS). Cells $(100,000)$ were placed in a flow cytometer tube and incubated with FITC Annexin-V (A5) and propidium iodide $(\mathrm{PI})$ for $15 \mathrm{~min}$. Stained cells were analyzed in an LSR II cytometer with FACSDiva software (BD Biosciences, Le Pont de Claix, France). Viable cells were defined as A5- and PI-negative cells.

\subsection{Cell adhesion}

Cell adhesion was determined by measuring the number of adherent cells using the CyQuant ${ }^{\circledR}$ GR Dyes, which generate intense fluorescence when bound to DNA (ThermoFisher Scientific, France). Briefly, macrophages $\left(10,000\right.$ cells $\left./ \mathrm{cm}^{2}\right)$ were placed in 96-well culture plates, treated (or not) with NTD for $2 \mathrm{~h}$, and cultured for up to $72 \mathrm{~h}$ with or without CSF1. The cells were then washed to eliminate floating cells and incubated with the 
CyQuant ${ }^{\circledR}$ GR Dyes for $1 \mathrm{~h}$ at room temperature. The number of adherent cells was directly proportional to the level of intracellular DNA and consequently to fluorescence intensity of the DNA-bound dye. Cell fluorescence was quantified on a POLARstar® Omega microplate reader (BMG Labtech, France), using excitation at $485 \mathrm{~nm}$ and emission at $530 \mathrm{~nm}$. Each experiment was repeated three times and each result is the mean of the three replicates.

\subsection{Western blotting}

Treated cells were lysed with a RIPA buffer containing $150 \mathrm{mM} \mathrm{NaCl}, 50 \mathrm{mM}$ Tris-HCL, $0.1 \%$ SDS, $1 \%$ Triton X-100, $0.5 \%$ Na deoxycholate, $50 \mathrm{mM}$ sodium fluoride (NaF), $5 \mathrm{mM}$ EDTA, 0.5 mM dithiothreitol, a protease inhibitor cocktail (Roche Diagnostic, Meylan, France) and phosphatase inhibitor cocktails 2 and 3 (Sigma-Aldrich). Whole cell lysates were centrifuged at $13000 \mathrm{rpm}$ for $5 \mathrm{~min}$ and the supernatants collected and heated at $95^{\circ} \mathrm{C}$ for 5 min to denature proteins. These lysates were placed onto $4 \%$ stacking gels and separated by SDS electrophoresis ( $8 \%$ or $10 \%$ gels). The separated proteins were transferred to nitrocellulose membranes by electroblotting overnight $\left(30 \mathrm{~V}\right.$ at $\left.4^{\circ} \mathrm{C}\right)$ and free binding sites were blocked by incubation in Tris-buffered saline containing $0.1 \%$ Tween 20 and $4 \%$ bovine serum albumin. The blocked membranes were incubated overnight at $4^{\circ} \mathrm{C}$ with the appropriate primary Abs (1/1000), then with horseradish peroxidase-conjugated secondary Abs (1/2000), and the visualised bands analysed by densitometry (Image Lab ${ }^{\mathrm{TM}}$ Software for total protein normalization; BioRad, Marnes-la-Coquette, France). The clone and reference of all Abs used for Western blot analysis are summarized in the Table S1.

\subsection{Flow cytometry}

Macrophage phenotypes were analysed by direct immunofluorescence using flow cytometry. Washed, detached cells were stained with Fixable Viability Stain 450 (BD Biosciences, Le Pont de Claix, France) for $10 \mathrm{~min}$ at room temperature to measure viability. Non-specific Ab binding sites on cells were blocked by incubating them in PBS containing $2 \%$ FBS and FcR blocking reagent (reference 130-059-901, Miltenyi Biotec SAS, Paris, France) for 10 min at 
room temperature. Cells were next incubated with a specific Ab or its isotypic control for 20 min at $4{ }^{\circ} \mathrm{C}$, washed in PBS and collected by centrifugation ( $2500 \mathrm{rpm}$ for $5 \mathrm{~min}$ ). Ab binding was analyzed in an LSR II cytometer and FACSDiva software. The M0, M1 and M2a macrophage phenotypes were characterized using three Ab panels. MO panel: FITC antiCD14, PE anti-CD206 and APC anti-CD71; M1 panel: FITC anti-CD86, PE anti-CD40, PeCya7 anti-CD80 and APC anti-CD83; M2a panel: APC anti-CD200R, PE anti-CD206, BB515 anti-CD11b and PEVio770 anti-CD209. The clone and reference of these Abs are summarized in the Table S2. Results are expressed as the ratio of median fluorescence intensity (MFI) calculated as: MFI (test Ab) / MFI (isotype control Ab).

\subsection{Reverse transcription quantitative polymerase chain reaction ( $R T-q P C R)$}

Total RNA was extracted from cells with the Trizol reagent (Thermo Fisher Scientific, France) and was submitted to reverse transcription using the High Capacity cDNA Reverse Transcription kit from Applied Biosystems (Thermo Fisher Scientific, France). Quantitative PCR were performed with the fluorescent dye SYBR Green methodology and a CFX384 real-time PCR system (BioRad) [21]. Primers for gene expression analysis were purchased from Sigma-Aldrich. The specificity of gene amplification was checked at the end of PCR by analyzing amplification curves using the comparative cycle threshold method (CFX Manager ${ }^{\mathrm{TM}}$ Software). This software automatically sets the fluorescence baseline for each well and computes the optimal quantification cycle $(\mathrm{Cq})$ with a multivariate, nonlinear regression model. These mean $\mathrm{Cq}$ values were used to normalize the steady-state target mRNA concentrations to those of the $18 \mathrm{~S}$ ribosomal protein by the $2(-\Delta \Delta \mathrm{Cq})$ method.

\subsection{Quantification of cytokines}

The amounts of human IL-1 $\beta$, IL-8, IL-10, CXCL13, PDGF-BB, CCL18, and CCL22 secreted into the medium of macrophage cultures were measured by ELISA (enzyme-linked immunosorbent assay) using appropriate Duoset ELISA development system kits (R\&D Systems Europe, Lille, France). 


\subsection{Statistic analysis}

The Gaussian distribution of values was first verified using D'Agostino \& Pearson and Kolmogrov-Smirnov tests. Since values followed a normal distribution, the results were presented as mean \pm standard deviation (SD) of the indicated numbers of independent experiments. Significant differences were assessed using a Student $t$-test when only two variables were studied in a same experiment or ANOVA followed by the multi-range Dunett's t-test when an experiment involved more than two variables. A paired Student t-test or a repeated ANOVA was used when the matching was effective. Differences between means were considered significant if $p<0.05$. 


\section{Results}

3.1 Influence of NTD on CSF1R-dependent signaling pathways in human MO macrophages

We first measured the kinetics of CSF1-dependent CSF1R phosphorylation in human M0 macrophages. The levels of phosphor-CSF1R was maximal after incubation for $1 \mathrm{~min}$ and then progressively decreased during $1 \mathrm{~h}$ (Fig. 1A). The binding of CSF1 to its receptor activates the PI3K and mitogen-activated protein kinase (MAPK) pathways, to ultimately trigger the phosphorylation of the serine/threonine kinases AKT (PI3K) and p42/p44 ERK (MAPK). Indeed, incubation with CSF1 for 1 to $5 \mathrm{~min}$ increased the phosphorylation of AKT and p42/p44 ERK in M0 macrophages. We used the PI3K inhibitor LY294002 and the CSF1R antagonist GW2580 to confirm the role of CSF1R in the phosphorylation of AKT and ERK. LY294002 totally blocked AKT phosphorylation but had no effect on the phosphorylation of CSF1R or p42/p44 ERK in macrophages incubated with CSF1 for 5 min (Fig. 1B). In contrast, GW2580 not only prevented the phosphorylation of CSF1R but also that of AKT and p42/p44 ERK. NTD inhibited, in a concentration-dependent manner, the phosphorylation of CSF1R in stimulated macrophages (Fig. 1C). NTD (10 nM) significantly decreased (approximately $50 \%$ ) the levels of phosphorylated CSF1R, while higher NTD concentrations $(\geq 200 \mathrm{nM})$ almost totally inhibited CSF1R phosphorylation in M0 macrophages. The drug also reduced the phosphorylation of AKT and p42/p44 ERK, but this effect was only significant for concentrations $\geq 100 \mathrm{nM}$ (AKT) or $200 \mathrm{nM}$ (ERK). Fig. S1 shows uncropped images of the original Western blots.

\subsection{NTD and adhesion of human MO macrophages}

We then determined cellular consequences of inhibiting the CSF1R-dependent signaling pathways in M0 macrophages. Human M0 macrophages cultured for $72 \mathrm{~h}$ with $50 \mathrm{ng} / \mathrm{ml}$ CSF1 remained spindle-shaped, adhered firmly and did not proliferate. Phase contrast microscopy shows that the number of adherent macrophages after culture without CSF1 for $72 \mathrm{~h}$ was much lower (Fig. 2A). Similarly, NTD caused the cells to round up and seemed to reduce adhesion in a concentration-dependent manner (Fig. 2A). We verified these effects by 
staining the nuclei of adherent macrophages and measuring cell fluorescence. Those cultured without CSF1 for $72 \mathrm{~h}$ (CTR) or containing CSF1 plus GW2580 or LY294002, had significantly fewer adherent macrophages (Figure 2B, left panel). NTD also caused a concentration-dependent reduction in macrophage adhesion (Fig. 2B, right panel). Its effect was detectable at $50 \mathrm{nM}$ and became significant at concentrations $\geq 200 \mathrm{nM}$. NTD (200 nM) reduced the number of adhering macrophages by $47.8 \%$. We next determined whether the cells became detached due to cytotoxicity by analyzing the viability of floating and adherent cells cultured for $72 \mathrm{~h}$ under the same experimental conditions. The percentage of viable cells cultured in the absence (CTR) or presence of CSF1 ("0") remained similar, when measured by flow cytometry using A5 and PI labelling (Figure 2C, left panel). NTD (10 to 200 $\mathrm{nM}$ ) was not cytotoxic, but $1 \mu \mathrm{M}$ NTD slightly (14.5\%) reduced cell viability (Fig. $2 \mathrm{C}$, left panel). Similarly, neither GW2580 nor LY294002 significantly modified the percentage of viable macrophages (Fig. $2 \mathrm{C}$, right panel). Thus, blocking CSF1R kinase activity promoted the detachment of M0 macrophages but did not affect their viability.

\subsection{Effect of NTD on MO marker production and CCL2 gene induction}

Human M0 macrophages bear the monocyte marker and TLR4 co-receptor CD14, but its expression is lower than that on human monocytes (Fig. 3A). As expected, the expression of the transferrin receptor CD71 and the mannose receptor CD206 are higher on M0 macrophages than on monocytes (Fig. 3A) $[8,22]$. The gating strategy and representative graphs are presented on the Figure S2A. The membrane expression of these M0 markers on cells cultured for $24 \mathrm{~h}$ in the absence of CSF1 (CTR) or with CSF1 in the presence of increasing concentrations of NTD were unchanged (Fig. 3B). Similarly, treating cells with CSF1 in the presence of GW2580 or LY294002 had no effect on their CD14, CD71 and CD206 membrane expression (data not shown). In contrast, M0 macrophages stimulated with CSF1 for $24 \mathrm{~h}$ significantly increased both CCL2 mRNA and protein levels (Fig. 3C). Blocking the CSF1R receptor with GW2580 and the PI3K/AKT pathway with LY294002 
greatly reduced CCL2 gene expression (Fig. 3C). NTD, like GW2580 and LY294002, significantly blocked the production of both CCL2 mRNA and protein (Fig. 3D).

\subsection{Influence of NTD on M1 and M2a markers}

Human M0 macrophages can be polarized to form classical "pro-inflammatory" M1 macrophages or alternative "pro-fibrotic" M2a macrophages, depending on their microenvironment [20]. We first checked the induction of membrane markers by culturing macrophages for $24 \mathrm{~h}$ with CSF1+LPS/INF (M1) or CSF1+IL-4/IL-13 (M2a). CD80, CD86, CD40 and CD83 were specifically induced in M1 macrophages whereas CD11b, CD200R, CD206 and CD209 were selectively increased in M2a macrophages (Figure 4A). The gating strategy and representative graphs are presented on the Figure S2B-C. GW2580 had no effect on M1 or M2a markers (data not shown), indicating that inhibiting CSF1R does not interfere with the intracellular process controlling $\mathrm{M} 1$ and $\mathrm{M} 2 \mathrm{a}$ polarization. We did not assess the effects of LY294002 as it inhibits the PI3K pathway induced by CSF1 and/or LPS/IFN. NTD did not modify the LPS/IFN-induced production of M1 markers but it did reduce the membrane concentrations of M2a markers (Fig. 4B). NTD ( $\geq 200 \mathrm{nM}$ ) significantly blocked the IL-4/IL-13-induced synthesis of CD11b, CD206 and CD209, indicating that NTD probably affects M2a polarization via a mechanism that is independent of CSF1R inhibition.

\subsection{Influence of NTD on the synthesis of cytokines in M1 and M2a macrophages}

We then investigated the influence of NTD on the synthesis of several specific M1 and M2a macrophage pro-inflammatory and/or pro-fibrotic genes. Inhibiting CSF1R with GW2850 did not prevent the induction of IL-1 $\beta, \mathrm{IL}-8$ and IL-10 mRNA and increased by $50 \%$ the CXCL13 mRNA levels (Fig. 5A). However, GW2580 significantly reduced the IL-1 $\beta$ and IL-8 secreted into the culture medium, without changing IL-10 or CXCL13 production (Fig. 5B). NTD ( $\geq 200 \mathrm{nM}$ ), like GW2580, did not inhibit the induction of IL-1 $\beta$ and IL-8 mRNA but it did significantly reduce IL-1 $\beta$ and IL-8 secretion (Fig. 5C and 5D). In contrast, unlike GW2850, NTD blocked, in a concentration-dependent manner, any increase in both mRNA and protein 
encoded by the IL-10 and CXCL13 genes. Consequently, this indicates that NTD does not alter IL-10 or CXCL13 gene expression by inhibiting CSF1R but rather by interacting with other targets.

Polarizing M2a macrophages with IL-4/L-13 increased the expression of the CCL18, CCL22 and PDGF-BB genes; but its influence on mRNA or protein production was genedependent (Fig. 6A and 6B). IL-4/LL-13 significantly increased the concentrations of CCL18 mRNA and protein; they also increased CCL22 mRNA levels without significantly enhancing CCL22 secretion. Conversely, IL-4/IL-13 did not increase PDGF-BB mRNA levels, while significantly enhancing PDGF-BB release from macrophages. GW2580 significantly increased CCL18 gene expression in M2a macrophages (Fig. 6A and 6B) and enhanced the production of CCL22 and PDGF-BB mRNAs but not secretion of the encoded proteins. Similarly, increasing concentrations of NTD enhanced CCL18 gene expression and protein secretion, resulting in significant effects at $1 \mu \mathrm{M}$ concentrations (Fig. 6C and 6D). Nevertheless, the effects of NTD on CCL22 and PDGF-BB gene expression were not significant. 


\section{Discussion}

We find that NTD markedly alters the phenotype of human macrophages, mainly by inhibiting the activation of CSF1R and modulating other molecular targets. It blocked the phosphorylation of CSF1R and the subsequent activation of the PI3K/AKT and MAPK/ERK signaling pathways induced by CSF1 in a concentration-dependent manner. The binding of CSF1 to its receptor leads to the dimerization of CSF1R and the rapid autophosphorylation of several tyrosine residues, including tyrosine 723 (Tyr-721 in the mouse). The PI3K/AKT pathway is activated in mouse macrophages following the interaction of the p85 regulatory subunit of PI3K with the phosphorylated tyrosine 721 [23], whereas the binding of the Grb2 adaptor protein to phosphorylated tyrosine residues in CSF1R is thought to trigger ERK activation [10]. We found that $10 \mathrm{nM}$ NTD reduces CSF1R phosphorylation by over $50 \%$, in agreement with the recent demonstration that NTD inhibits the kinase activity of recombinant human CSF1R protein ( $\left.\mathrm{IC}_{50}: 5 \pm 2 \mathrm{nM}\right)$ [9]. However, $10 \mathrm{nM}$ NTD did not prevent the phosphorylation of AKT or ERK. The amount of phosphorylated AKT and ERK were only significantly decreased in macrophages treated with NTD concentrations above $100 \mathrm{nM}$. Since $10 \mathrm{nM}$ NTD partially blocks CSF1R phosphorylation in CSF1-stimulated macrophages, the CSF1R activity detected in macrophages treated with $10 \mathrm{nM}$ NTD is probably still sufficient to allow the binding of both p85-PI3K and Grb2, and thus to fully activate AKT (p85PI3K) and ERK (Grb2). This evidence that CSF1R is a new molecular target of NTD should be taken into account when investigating effects of the drug on myeloid or tumor cells bearing this receptor.

The inhibition of CSF1R phosphorylation by NTD also influences the function of human macrophages. It markedly reduced cell adhesion and triggered macrophage rounding without being cytotoxic. These effects were concentration-dependent and significant at NTD concentrations above $200 \mathrm{nM}$. We obtained evidence suggesting that NTD decreases cell adhesion by preventing the activation of the CSF1R-dependent PI3K pathway. First, culturing macrophages in the absence of CSF1 or in the presence of the CSF1R inhibitor, GW2580, 
mimicked the effect of NTD on macrophage adhesion and morphology. Second, the PI3K inhibitor LY294002, like NTD, strongly inhibited the adhesion of human macrophages. And third, actin cytoskeleton remodeling, which controls cell adhesion and motility in mouse macrophages, is tightly regulated by the PI3K-dependent activation of paxillin, a major protein in macrophage focal complexes [24]. However, inhibiting CSF1R activity with NTD or GW2580 did not alter cell viability, suggesting that survival pathways induced by CSF1 during monocyte differentiation are not controlled by this receptor in mature macrophages. Similarly, NTD and GW2580 did not decrease the membrane expression of CD71 and CD206, two M0 markers absent from monocytes. The levels of CD71 and CD206 were unchanged and are thus independent of CSF1R activity in mature macrophages.

NTD, like GW2580, blocked any increases in CCL2 mRNA or protein, in agreement with the findings of Baran et al (2007), who reported that CSF1 induced CCL2 gene expression in mouse bone marrow- and human monocyte-derived macrophages [12]. CCL2 plays a major role in murine lung fibrosis especially by promoting monocyte and phagocyte recruitment [12]. In their study, Bara et al (2007) demonstrated that CCL2 $2^{-/-}$mice treated with bleomycin had less cell infiltration in pulmonary tissue, interstitial lung thickening and collagen deposition in lungs than wild-type mice. Moreover, they found that bronchoalveolar lavages of patients with IPF contain increased CCL2 concentrations, suggesting that this chemokine is involved in the development of lung fibrosis in humans. Finally, we found that LY294002 almost totally prevented the increase in CCL2 mRNA, indicating that the CSF1R-dependent expression of the CCL2 gene is positively regulated by the PI3K pathway in human macrophages.

Blocking CSF1R with NTD or GW2580 altered the cytokine profiles in M1 and M2a macrophages differently. They did not prevent the induction of M1 markers, but they significantly reduced the secretion of IL-1 $\beta$ and IL- 8 by M1 macrophages. As neither NTD nor GW2580 impaired IL-1 $1 \beta$ or IL-8 mRNA production, they probably interfere with protein synthesis. It is generally accepted that the maturation of IL-1 $\beta$ in macrophage is controlled 
mainly post-translationally, by the NOD-like receptor pyrin domain 3 (NLRP3) inflammasome, a cytoplasmic protein complex [25]. IL-1 $\beta$ gene induction by LPS results in pro-IL-1 $\beta$, which is cleaved to give its mature form by the cysteine protease caspase- 1 . This protease is the effector molecule of the inflammasome that also contains the sensor protein NLRP3 and the adaptor ASC [25]. Gaidt et al. (2016) recently reported that a caspase 8-dependent signaling system mediates the assembly of the NLRP3 inflammasome in human monocytes stimulated with LPS [26]. The differentiation of human monocytes induced by CSF1 also requires activation of caspase-8, which is essential for cell survival [27]. The fact that NTD and GW2580 specifically decreased the secretion of IL-1 $\beta$ suggests that stimulating CSF1R with CSF1 favors the assembly of the NLRP3 inflammasome, which was induced with silica in our study (Fig. 5D), perhaps by re-activating caspase 8 and triggering a caspase-8-dependent signaling pathway upstream of NLRP3. Yet, no evidence of caspase-8 function in CSF1induced macrophages is reported. How NTD or GW2580 interferes with IL-8 production is also elusive, as the process controlling IL-8 maturation is poorly understood. Nevertheless, treating rheumatoid arthritis synovial explants with an anti-human CSF1R monoclonal antibody greatly reduces the CSF1-induced release of IL-8 [28]. Hence, CSF1R may well play a positive role in the regulation of IL-8 production, at least in vitro.

While NTD and GW2580 seemed to have no effect on the secretion of CCL22 and PDGFBB by M2a macrophages, they did increase the release of CCL18 from human macrophages polarized with IL-4/IL-13. They also significantly enhanced CCL18 mRNA production, suggesting that activating CSF1R probably blocks transcription of the CCL18 gene by altering a signaling pathway induced by IL-4/IL-13. Thus, CSF1 not only promotes adhesion, it also increases or represses the expression of genes that help define the overall phenotype of mature macrophages.

Besides inhibiting CSF1R activation, NTD also appeared to alter the polarization of M0 macrophages by interacting with other molecular targets. Specifically, NTD prevented the expression of the IL-10 and CXCL13 genes in M1 macrophages, whereas GW2580 had no 
significant effect. It may be possible that NTD prevented the production of these cytokines by blocking the Bruton's tyrosine kinase (Btk). Indeed, LPS rapidly activates Btk in murine and human macrophages, and inhibiting Btk with the selective inhibitor, Ibrutinib, markedly reduces the increases in IL-10 and CXCL13 mRNAs induced by LPS [29,30]. However, it is not clear whether Btk stimulates the CXCL13 gene directly, since macrophage treatment with an Ab neutralizing IL-10 significantly reduces CXC13 production [31]. In cell-free systems, NTD also inhibits the kinase activity of the human recombinant Btk protein $\left(\mathrm{IC}_{50}: 34 \mathrm{nM}\right)[9]$. Studies on human macrophages stimulated with LPS are thus needed to determine whether Btk is a new molecular target of NTD. Finally, 200 nM NTD significantly reduced the increases in the M2a markers CD11b, CD206 and CD209 independently of CSF1R inhibition. NTD concentrations as low as $50 \mathrm{nM}$ significantly reduced the membrane expression of CD206 induced by IL-4/IL-13. It can be noted that Huang et al. (2017) previously reported that NTD partially prevents the expression of CD206 in human M2 macrophages, however without investigating the role of CSF1R [8]. NTD may prevent M2a polarization independently of Btk, since ibrutinib does not seem to alter signaling induced by IL-4 [32]. NTD might reduce the expression of $\mathrm{M} 2 \mathrm{a}$ markers by inhibiting the Src kinase Hck that mediates the CD206 gene activity induced by IL-13 in human monocytes [33]. NTD inhibit several Src kinases [9,34], but its effect on Hck kinase activity remains to be demonstrated. Altogether, our results strongly suggest that NTD likely altered the phenotype and the polarization of human macrophages, not only by inhibiting CSF1R activity, but also by repressing other kinases that remain to be characterized.

More generally, our results demonstrate that, in vitro, NTD exerts anti-inflammatory effects by blocking the expression of the IL-1 $\beta, I L-8, I L-10$, CCL2 and CXCL13 genes that contribute to lung fibrosis [35-37]. Therefore, these results support recent findings concerning the antiinflammatory properties of NTD in murine models of fibrosis $[4,6-8]$. However, the clinical relevance of these effects should be further investigated since NTD alters macrophage functions in vitro at concentrations higher than those measured in patients with IPF after 
standard dosing [18]. Indeed, NTD significantly altered the phenotype of macrophages only when it was used at concentrations above $200 \mathrm{nM}$, whereas the highest blood concentrations measured in patients with IPF are about $70 \mathrm{nM}$. Future clinical trials may assess the immunomodulatory properties of NTD by measuring blood concentrations of various cytokines before and after treatment.

\section{Conclusion}

NTD inhibits the activation of CSF1R, which is therefore a new molecular target of the drug. NTD has anti-inflammatory effects on human macrophages, mainly due to CSF1R inhibition, but also from interactions with other as-yet unidentified targets.

\section{Acknowledgements}

This work was supported by the Institut National de la Santé et de la Recherche Médicale (INSERM), the Université de Rennes (Univ Rennes) and Boehringer Ingelheim Pharma $\mathrm{GmbH}$. Nessrine Bellamri holds a fellowship funded by the University of Rennes. We thank the Rennes Biosit platform for flow cytometry and Professor Olivier Fardel for helpful comments and critically reading the manuscript. Dr Owen Parkes edited the English text.

\section{Conflict of interest}

Dr Stefan-Lutz Wollin is an employee of Boehringer Ingelheim the company who invented nintedanib, the drug used in this study. Pr Stéphane Jouneau has received fees, funding or reimbursement for national and international conferences, boards, expert or opinion groups, research projects over the past 5 years from Actelion, AIRB, Astra Zeneca, BMS, Boehringer, Chiesi, Gilead, GSK, LVL, Mundipharma, Novartis, Pfizer, Roche, Savara-Serendex. The other authors declare no competing interests. 


\section{References}

[1] G. Sgalla, B. lovene, M. Calvello, M. Ori, F. Varone, L. Richeldi, Idiopathic pulmonary fibrosis: pathogenesis and management, Respir. Res. $19 \quad$ (2018) 32. doi:10.1186/s12931-018-0730-2.

[2] L. Richeldi, R.M. du Bois, G. Raghu, A. Azuma, K.K. Brown, U. Costabel, V. Cottin, K.R. Flaherty, D.M. Hansell, Y. Inoue, D.S. Kim, M. Kolb, A.G. Nicholson, P.W. Noble, M. Selman, H. Taniguchi, M. Brun, F. Le Maulf, M. Girard, S. Stowasser, R. SchlenkerHerceg, B. Disse, H.R. Collard, INPULSIS Trial Investigators, Efficacy and safety of nintedanib in idiopathic pulmonary fibrosis, N. Engl. J. Med. 370 (2014) 2071-2082. doi:10.1056/NEJMoa1402584.

[3] L. Wollin, E. Wex, A. Pautsch, G. Schnapp, K.E. Hostettler, S. Stowasser, M. Kolb, Mode of action of nintedanib in the treatment of idiopathic pulmonary fibrosis, Eur. Respir. J. 45 (2015) 1434-1445. doi:10.1183/09031936.00174914.

[4] L. Wollin, I. Maillet, V. Quesniaux, A. Holweg, B. Ryffel, Antifibrotic and antiinflammatory activity of the tyrosine kinase inhibitor nintedanib in experimental models of lung fibrosis, J. Pharmacol. Exp. Ther. $349 \quad$ (2014) 209-220. doi:10.1124/jpet.113.208223.

[5] K.E. Hostettler, J. Zhong, E. Papakonstantinou, G. Karakiulakis, M. Tamm, P. Seidel, Q. Sun, J. Mandal, D. Lardinois, C. Lambers, M. Roth, Anti-fibrotic effects of nintedanib in lung fibroblasts derived from patients with idiopathic pulmonary fibrosis, Respir. Res. 15 (2014) 157. doi:10.1186/s12931-014-0157-3.

[6] B. Öztürk Akcora, G. Storm, J. Prakash, R. Bansal, Tyrosine kinase inhibitor BIBF1120 ameliorates inflammation, angiogenesis and fibrosis in CCl4-induced liver fibrogenesis mouse model, Sci Rep. 7 (2017) 44545. doi:10.1038/srep44545.

[7] F. Liu, L. Wang, H. Qi, J. Wang, Y. Wang, W. Jiang, L. Xu, N. Liu, S. Zhuang, Nintedanib, a triple tyrosine kinase inhibitor, attenuates renal fibrosis in chronic kidney disease, Clin. Sci. 131 (2017) 2125-2143. doi:10.1042/CS20170134. 
[8] J. Huang, C. Maier, Y. Zhang, A. Soare, C. Dees, C. Beyer, U. Harre, C.-W. Chen, O. Distler, G. Schett, L. Wollin, J.H.W. Distler, Nintedanib inhibits macrophage activation and ameliorates vascular and fibrotic manifestations in the Fra2 mouse model of systemic sclerosis, Ann. Rheum. Dis. 76 (2017) 1941-1948. doi:10.1136/annrheumdis2016-210823.

[9] F. Hilberg, U. Tontsch-Grunt, A. Baum, A.T. Le, R.C. Doebele, S. Lieb, D. Gianni, T. Voss, P. Garin-Chesa, C. Haslinger, N. Kraut, Triple Angiokinase Inhibitor Nintedanib Directly Inhibits Tumor Cell Growth and Induces Tumor Shrinkage via Blocking Oncogenic Receptor Tyrosine Kinases, J. Pharmacol. Exp. Ther. 364 (2018) 494-503. doi:10.1124/jpet.117.244129.

[10] F.J. Pixley, E.R. Stanley, CSF-1 regulation of the wandering macrophage: complexity in action, Trends Cell Biol. 14 (2004) 628-638. doi:10.1016/j.tcb.2004.09.016.

[11] D. Achkova, J. Maher, Role of the colony-stimulating factor (CSF)/CSF-1 receptor axis in cancer, Biochem. Soc. Trans. 44 (2016) 333-341. doi:10.1042/BST20150245.

[12] C.P. Baran, J.M. Opalek, S. McMaken, C.A. Newland, J.M. O'Brien, M.G. Hunter, B.D. Bringardner, M.M. Monick, D.R. Brigstock, P.C. Stromberg, G.W. Hunninghake, C.B. Marsh, Important roles for macrophage colony-stimulating factor, $\mathrm{CC}$ chemokine ligand 2, and mononuclear phagocytes in the pathogenesis of pulmonary fibrosis, Am. J. Respir. Crit. Care Med. 176 (2007) 78-89. doi:10.1164/rccm.200609-12790C.

[13] L. Meziani, M. Mondini, B. Petit, A. Boissonnas, V. Thomas de Montpreville, O. Mercier, M.-C. Vozenin, E. Deutsch, CSF1R inhibition prevents radiation pulmonary fibrosis by depletion of interstitial macrophages, Eur. Respir. J. 51 (2018). doi:10.1183/13993003.02120-2017.

[14] L. Morales-Nebreda, A.V. Misharin, H. Perlman, G.R.S. Budinger, The heterogeneity of lung macrophages in the susceptibility to disease, Eur Respir Rev. 24 (2015) 505-509. doi:10.1183/16000617.0031-2015. 
[15] A.V. Misharin, L. Morales-Nebreda, P.A. Reyfman, C.M. Cuda, J.M. Walter, A.C. McQuattie-Pimentel, C.-I. Chen, K.R. Anekalla, N. Joshi, K.J.N. Williams, H. AbdalaValencia, T.J. Yacoub, M. Chi, S. Chiu, F.J. Gonzalez-Gonzalez, K. Gates, A.P. Lam, T.T. Nicholson, P.J. Homan, S. Soberanes, S. Dominguez, V.K. Morgan, R. Saber, A. Shaffer, M. Hinchcliff, S.A. Marshall, A. Bharat, S. Berdnikovs, S.M. Bhorade, E.T. Bartom, R.I. Morimoto, W.E. Balch, J.I. Sznajder, N.S. Chandel, G.M. Mutlu, M. Jain, C.J. Gottardi, B.D. Singer, K.M. Ridge, N. Bagheri, A. Shilatifard, G.R.S. Budinger, H. Perlman, Monocyte-derived alveolar macrophages drive lung fibrosis and persist in the lung over the life span, J. Exp. Med. $214 \quad$ (2017) 2387-2404. doi:10.1084/jem.20162152.

[16] M.A. Gibbons, A.C. MacKinnon, P. Ramachandran, K. Dhaliwal, R. Duffin, A.T. Phythian-Adams, N. van Rooijen, C. Haslett, S.E. Howie, A.J. Simpson, N. Hirani, J. Gauldie, J.P. Iredale, T. Sethi, S.J. Forbes, Ly6Chi monocytes direct alternatively activated profibrotic macrophage regulation of lung fibrosis, Am. J. Respir. Crit. Care Med. 184 (2011) 569-581. doi:10.1164/rccm.201010-17190C.

[17] C.A. Ambarus, S. Krausz, M. van Eijk, J. Hamann, T.R.D.J. Radstake, K.A. Reedquist, P.P. Tak, D.L.P. Baeten, Systematic validation of specific phenotypic markers for in vitro polarized human macrophages, J. Immunol. Methods. 375 (2012) 196-206. doi:10.1016/j.jim.2011.10.013.

[18] T. Ogura, H. Taniguchi, A. Azuma, Y. Inoue, Y. Kondoh, Y. Hasegawa, M. Bando, S. Abe, Y. Mochizuki, K. Chida, M. Klüglich, T. Fujimoto, K. Okazaki, Y. Tadayasu, W. Sakamoto, Y. Sugiyama, Safety and pharmacokinetics of nintedanib and pirfenidone in idiopathic pulmonary fibrosis, Eur. Respir. J. 45 (2015) 1382-1392. doi:10.1183/09031936.00198013.

[19] A. Lescoat, A. Ballerie, Y. Augagneur, C. Morzadec, L. Vernhet, O. Fardel, P. Jégo, S. Jouneau, V. Lecureur, Distinct Properties of Human M-CSF and GM-CSF MonocyteDerived Macrophages to Simulate Pathological Lung Conditions In Vitro: Application to 
Systemic and Inflammatory Disorders with Pulmonary Involvement, Int J Mol Sci. 19 (2018). doi:10.3390/ijms19030894.

[20] M. Jaguin, N. Houlbert, O. Fardel, V. Lecureur, Polarization profiles of human M-CSFgenerated macrophages and comparison of M1-markers in classically activated macrophages from GM-CSF and M-CSF origin, Cell. Immunol. 281 (2013) 51-61. doi:10.1016/j.cellimm.2013.01.010.

[21] H. Pfister, C. Morzadec, P. Le Cann, L. Madec, V. Lecureur, M. Chouvet, S. Jouneau, L. Vernhet, Granulometry, microbial composition and biological activity of dusts collected in French dairy farms, Environ. Res. 158 (2017) 691-702. doi:10.1016/j.envres.2017.07.025.

[22] S. Boulakirba, A. Pfeifer, R. Mhaidly, S. Obba, M. Goulard, T. Schmitt, P. Chaintreuil, A. Calleja, N. Furstoss, F. Orange, S. Lacas-Gervais, L. Boyer, S. Marchetti, E. Verhoeyen, F. Luciano, G. Robert, P. Auberger, A. Jacquel, IL-34 and CSF-1 display an equivalent macrophage differentiation ability but a different polarization potential, Sci Rep. 8 (2018) 256. doi:10.1038/s41598-017-18433-4.

[23] N.G. Sampaio, W. Yu, D. Cox, J. Wyckoff, J. Condeelis, E.R. Stanley, F.J. Pixley, Phosphorylation of CSF-1R Y721 mediates its association with PI3K to regulate macrophage motility and enhancement of tumor cell invasion, J. Cell. Sci. 124 (2011) 2021-2031. doi:10.1242/jcs.075309.

[24] E.R. Stanley, V. Chitu, CSF-1 receptor signaling in myeloid cells, Cold Spring Harb Perspect Biol. 6 (2014). doi:10.1101/cshperspect.a021857.

[25] Y. He, H. Hara, G. Núñez, Mechanism and Regulation of NLRP3 Inflammasome Activation, Trends Biochem. Sci. 41 (2016) 1012-1021. doi:10.1016/j.tibs.2016.09.002.

[26] M.M. Gaidt, T.S. Ebert, D. Chauhan, T. Schmidt, J.L. Schmid-Burgk, F. Rapino, A.A.B. Robertson, M.A. Cooper, T. Graf, V. Hornung, Human Monocytes Engage an Alternative Inflammasome Pathway, Immunity. $44 \quad$ (2016) 833-846. doi:10.1016/j.immuni.2016.01.012. 
[27] C. Rébé, S. Cathelin, S. Launay, R. Filomenko, L. Prévotat, C. L’Ollivier, E. Gyan, O. Micheau, S. Grant, A. Dubart-Kupperschmitt, M. Fontenay, E. Solary, Caspase-8 prevents sustained activation of NF-kappaB in monocytes undergoing macrophagic differentiation, Blood. 109 (2007) 1442-1450. doi:10.1182/blood-2006-03-011585.

[28] S. Garcia, L.M. Hartkamp, B. Malvar-Fernandez, I.E. van Es, H. Lin, J. Wong, L. Long, J.A. Zanghi, A.L. Rankin, E.L. Masteller, B.R. Wong, T.R.D.J. Radstake, P.P. Tak, K.A. Reedquist, Colony-stimulating factor (CSF) 1 receptor blockade reduces inflammation in human and murine models of rheumatoid arthritis, Arthritis Res. Ther. 18 (2016) 75. doi:10.1186/s13075-016-0973-6.

[29] N.W. Schmidt, V.T. Thieu, B.A. Mann, A.-N.N. Ahyi, M.H. Kaplan, Bruton's tyrosine kinase is required for TLR-induced IL-10 production, J. Immunol. 177 (2006) 72037210.

[30] L. Ping, N. Ding, Y. Shi, L. Feng, J. Li, Y. Liu, Y. Lin, C. Shi, X. Wang, Z. Pan, Y. Song, J. Zhu, The Bruton's tyrosine kinase inhibitor ibrutinib exerts immunomodulatory effects through regulation of tumor-infiltrating macrophages, Oncotarget. 8 (2017) 3921839229. doi:10.18632/oncotarget.16836.

[31] P. Perrier, F.O. Martinez, M. Locati, G. Bianchi, M. Nebuloni, G. Vago, F. Bazzoni, S. Sozzani, P. Allavena, A. Mantovani, Distinct transcriptional programs activated by interleukin-10 with or without lipopolysaccharide in dendritic cells: induction of the B cell-activating chemokine, CXC chemokine ligand 13, J. Immunol. 172 (2004) 70317042.

[32] S. Fiorcari, R. Maffei, V. Audrito, S. Martinelli, E. Ten Hacken, P. Zucchini, G. Grisendi, L. Potenza, M. Luppi, J.A. Burger, S. Deaglio, R. Marasca, Ibrutinib modifies the function of monocyte/macrophage population in chronic lymphocytic leukemia, Oncotarget. 7 (2016) 65968-65981. doi:10.18632/oncotarget.11782. 
[33] A. Bhattacharjee, S. Pal, G.M. Feldman, M.K. Cathcart, Hck is a key regulator of gene expression in alternatively activated human monocytes, J. Biol. Chem. 286 (2011) 36709-36723. doi:10.1074/jbc.M111.291492.

[34] L.-F. Li, K.-C. Kao, Y.-Y. Liu, C.-W. Lin, N.-H. Chen, C.-S. Lee, C.-W. Wang, C.-T. Yang, Nintedanib reduces ventilation-augmented bleomycin-induced epithelialmesenchymal transition and lung fibrosis through suppression of the Src pathway, J. Cell. Mol. Med. 21 (2017) 2937-2949. doi:10.1111/jcmm.13206.

[35] S. Kolahian, I.E. Fernandez, O. Eickelberg, D. Hartl, Immune Mechanisms in Pulmonary Fibrosis, Am. J. Respir. Cell. Mol. Biol. 55 (2016) 309-322. doi: 10.1165/rcmb.20160121TR.

[36] T.J. Richards, N. Kaminski, F. Baribaud, S. Flavin, C. Brodmerkel, D. Horowitz, K. Li, J. Choi, L.J. Vuga, K.O. Lindell, M. Klesen, Y. Zhang, K.F. Gibson, Peripheral blood proteins predict mortality in idiopathic pulmonary fibrosis, Am. J. Respir. Crit. Care Med. 185 (2012) 67-76. doi: 10.1164/rccm.201101-0058OC.

[37] L.J. Vuga, J.R. Tedrow, K.V. Pandit, J. Tan, D.J. Kass, J. Xue, D. Chandra, J.K. Leader, K.F. Gibson, N. Kaminski, F.C. Sciurba, S.R. Duncan, (CXCL13) is a prognostic biomarker of idiopathic pulmonary fibrosis, Am J Respir Crit Care Med. 189 (2014) 966974. doi: 10.1164/rccm.201309-1592OC. C-X-C motif chemokine 13 


\section{Legends}

Figure 1. NTD inhibits CSF1-induced CSF1R phosphorylation and downstream signaling pathways in human monocyte-derived macrophages. Macrophages were washed and left untreated (CTR, 0) (A-C), incubated with $10 \mu \mathrm{M}$ LY294002 (LY) (B), $10 \mu \mathrm{M}$ GW2580 (GW) (B) or NTD at 10-1000 $\mathrm{nM}(\mathrm{C})$, and then stimulated with $50 \mathrm{ng} / \mathrm{ml} \mathrm{CSF1}$. Cells were then lysed and analyzed by Western blotting. (A, C): right panel, the levels on phospho (p)-CSF$1 R, p-A K T$ and $p-E R K$ were measured by densitometry. The results are means \pm SD of $5(A)$ and 8 (C) independent experiments. (B): blots are representative of 4 independent experiments. * $p<0.05,{ }^{* *} p<0.01,{ }^{* * *} p<0.001$ versus " 0 ".

Figure 2. NTD decreases the CSF1-dependent adhesion of macrophages. After washing, monocyte-derived macrophages (CTR, $0 \mathrm{~h}$ ) were: left untreated (CTR, 0), incubated with 10 $\mu \mathrm{M}$ GW2580, $10 \mu \mathrm{M}$ LY294002 or NTD at 10-1000 nM, and then cultured without (CTR, $72 \mathrm{~h}$ ) or with $50 \mu \mathrm{g} / \mathrm{ml} \mathrm{CSF1}$ for $72 \mathrm{~h}$. (A): Phase contrast microscopy (representative of 5 independent experiments) x40. (B): cell adhesion quantified using the Cyquant GR dyes. (C): cell viability measured by flow cytometry - apoptotic (annexin- $\mathrm{V}, \mathrm{A} 5$ ) and/or necrotic (propidium iodide, PI) cells. Viable cells were defined as A5- and PI-negative macrophages. The results are means $\pm S D$ of 4 independent experiments. ${ }^{*} p<0.05,{ }^{* *} p<0.01,{ }^{* * *} p<0.001$ versus "0".

Figure 3. Effect of NTD on membrane expression of M0 markers and CCL2 expression. Fresh peripheral blood monocytes (Mono) and monocyte-derived macrophages at day 6 (M0) (A), M0 macrophages untreated $(C T R, 0)$ or incubated with NTD and then cultured in the absence (CTR) or presence of CSF1 for $24 \mathrm{~h}(\mathrm{~B})$, were analyzed by flow cytometry to measure membrane expression of the CD14, CD71 and CD206 markers. In (C), M0 macrophages were left untreated (CTR, 0) or incubated with $10 \mu \mathrm{M}$ GW2580 (GW), $10 \mu \mathrm{M}$ LY294002 (LY) or NTD at 10-1000 nM, and then cultured without (CTR) or with CSF1 for 24 h. CCL2 mRNA levels were measured by quantitative RT-PCR and normalized to endogenous ribosomal 18S RNA levels. Data are expressed relative to mRNA levels found in 
cells stimulated with CSF1 ("0"), arbitrarily set at 1. CCL2 in the culture media was quantified by ELISA. The results are means \pm SD of $4(A, B, C)$ and $6(D)$ independent experiments. * $p<0.05,{ }^{* *} p<0.01,{ }^{* * *} p<0.001$ versus "Mono" $(A)$ and versus " 0 " $(C, D)$.

Figure 4. NTD reduces expression of $\mathrm{M} 2 \mathrm{a}$ macrophage membrane markers. M0 macrophages were untreated (A, B) or incubated with NTD at 50-1000 nM (B) and then polarized into classical M1 (LPS/INF) or alternative M2a (IL-4/IL-13) macrophages for $24 \mathrm{~h}$. Membrane expression of the M1 and M2a markers was analyzed by flow cytometry. Results are the means $\pm S D$ of $6(A)$ and $4(B)$ independent experiments. ${ }^{*} p<0.05,{ }^{* *} p<0.01,{ }^{* \star *} p<$ 0.001 versus "M1" (A, top panel), M2a (A, bottom panel) or " 0 " (B).

Figure 5. Influence of NTD on the induction of pro-inflammatory and pro-fibrotic genes in M1 macrophages. Macrophages were untreated (M0, 0), treated with $10 \mu \mathrm{M}$ GW2580 (GW) or NTD at 50-1000 nM, and then left unstimulated (M0) or polarized to M1 macrophages by incubation with LPS/IFN (L/I) for $24 \mathrm{~h}$. IL-1 $\beta$ secretion was measured in cells stimulated with LPS/IFN (L/I) for $4 \mathrm{~h}$ and then with LPS/IFN $+100 \mu \mathrm{g} / \mathrm{ml}$ crystalline silica (L/I/Si) for $16 \mathrm{~h}$. mRNA levels were determined by quantitative RT-PCR and normalized to endogenous ribosomal 18S RNA levels. Data are expressed relative to mRNA levels found in LPS/IFNstimulated cells ("0") (A, C), arbitrarily set at $1 . \mathrm{IL}-1 \beta, \mathrm{IL}-8, \mathrm{IL}-10$ and CXCL13 in culture media were quantified by ELISA. Results are expressed as means \pm SD of $4(A, B), 6(C)$ and 5 to 8 (D) independent experiments. " $p<0.05$, ${ }^{* *} p<0.01,{ }^{* * *} p<0.001$ versus " 0 ".

Figure 6. Effects of NTD on CCL18, CCL22 and PDGF-BB expression in M2a macrophages. Macrophages were untreated (M0, 0), incubated with $10 \mu \mathrm{M}$ GW2580 (GW), or NTD at 50$1000 \mathrm{nM}$, and then left unstimulated (M0) or polarized to M2a macrophages by incubation with IL-4/IL-13 (IL4/IL13) for 24 h. mRNA levels were determined by quantitative RT-PCR and normalized to endogenous ribosomal 18S RNA levels. Data are expressed relative to mRNA levels found in IL4/IL13-stimulated cells ("0") (A, C), arbitrarily set at 1. The CCL18, CCL22 and PDGF-BB in culture media were quantified by ELISA. Results are expressed as means \pm 
SD of $4(A, B), 5(C)$ and 4 to 7 (D) independent experiments. ${ }^{*} p<0.05,{ }^{* *} p<0.01,{ }^{* * *} p<$ 0.001 versus " 0 ". 

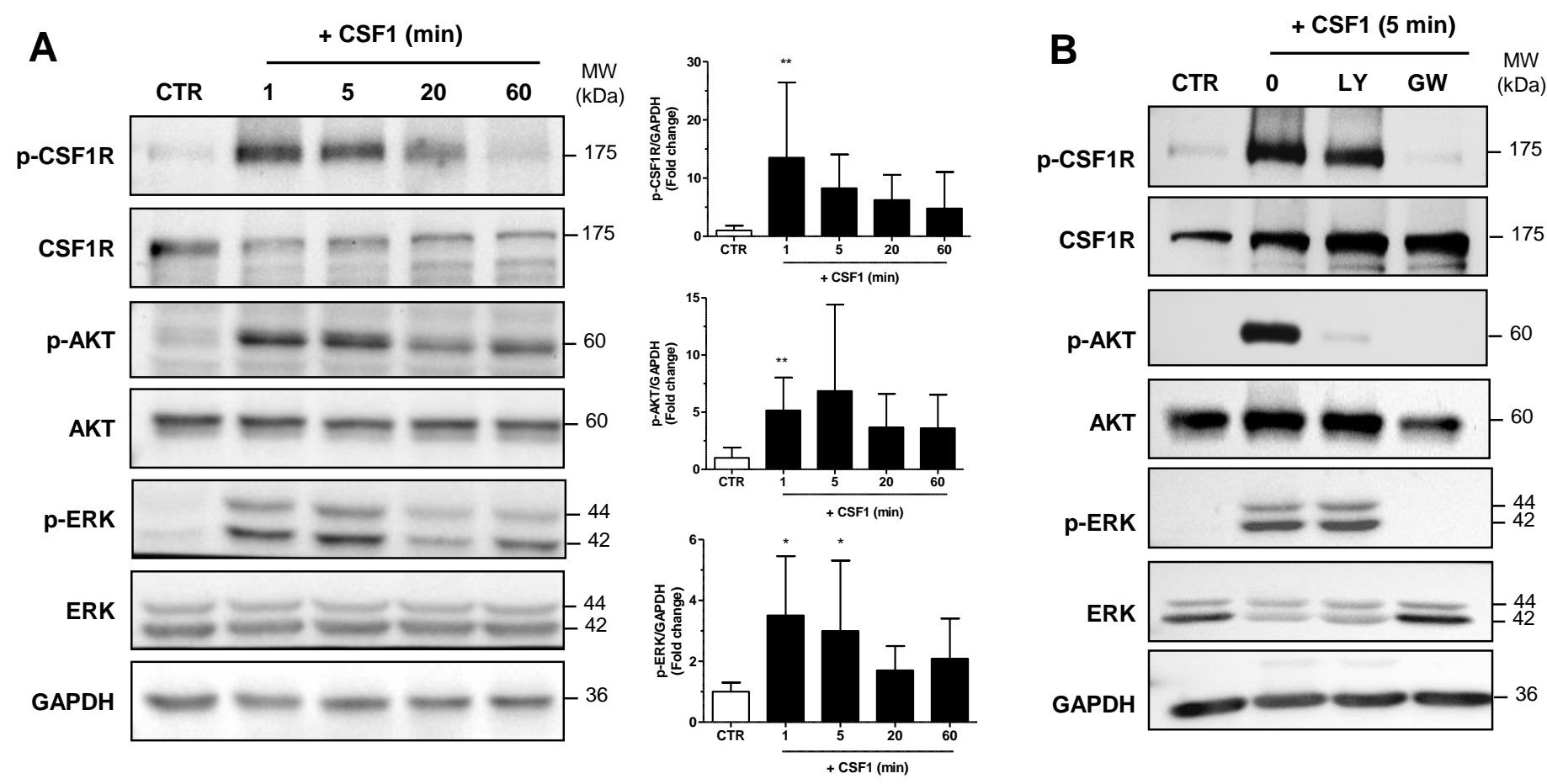
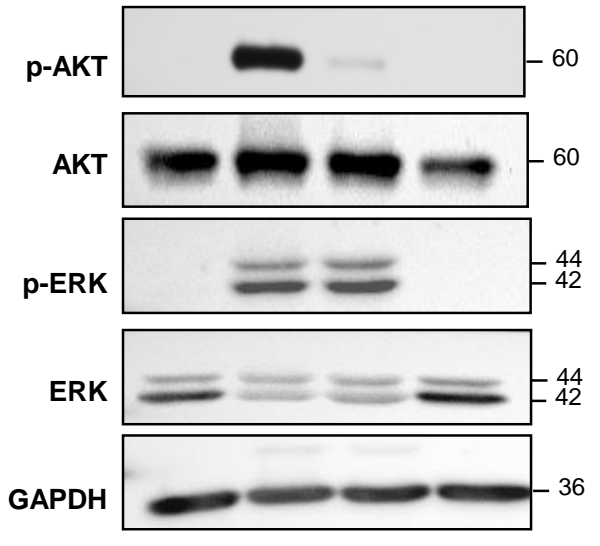

C
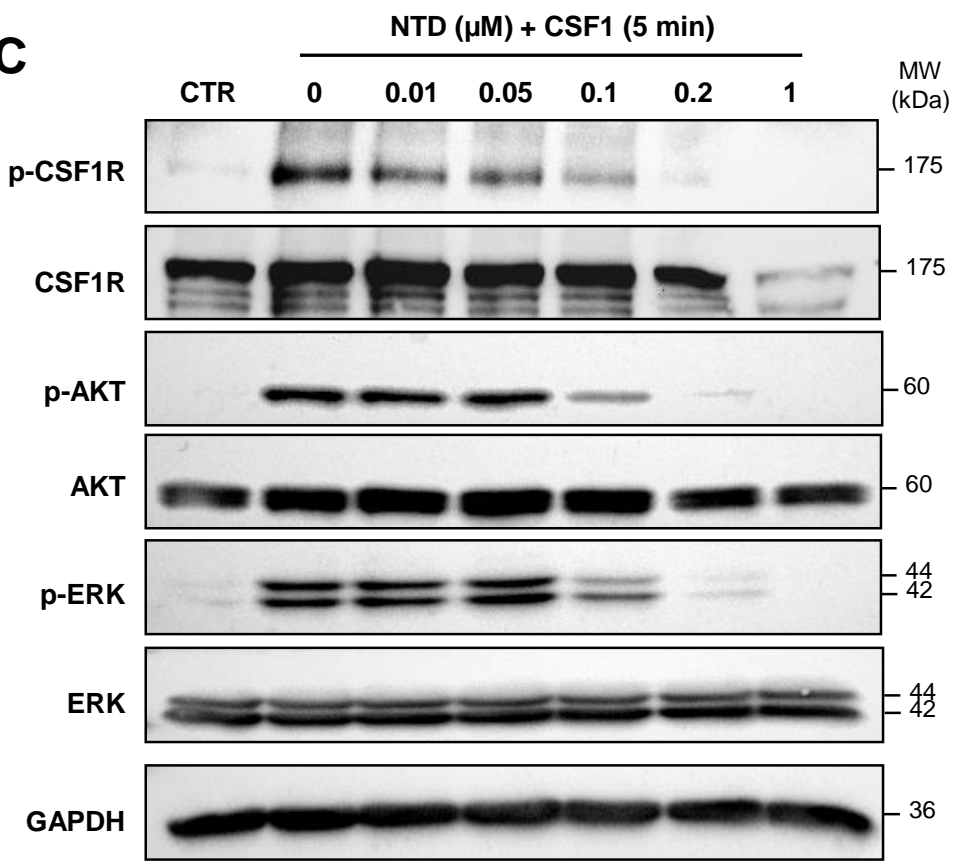
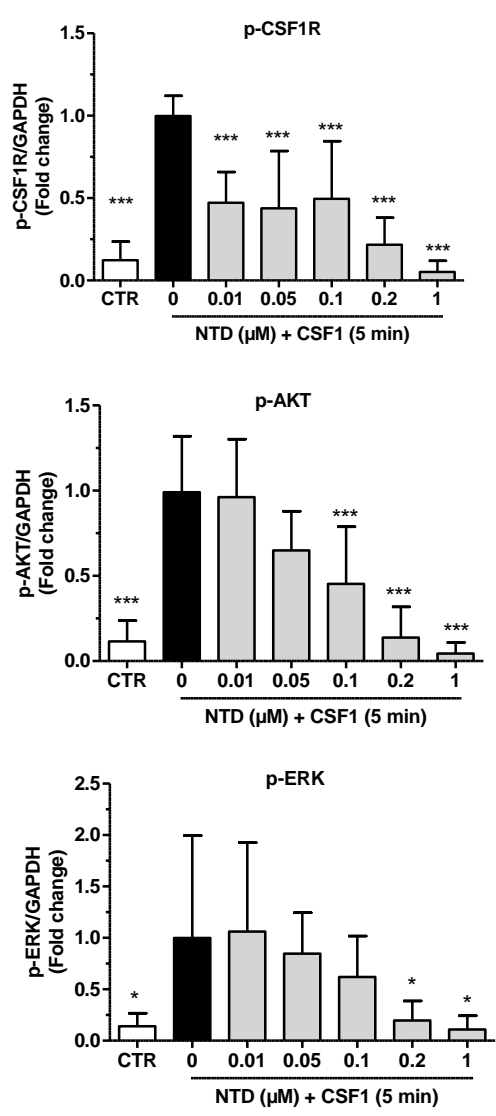

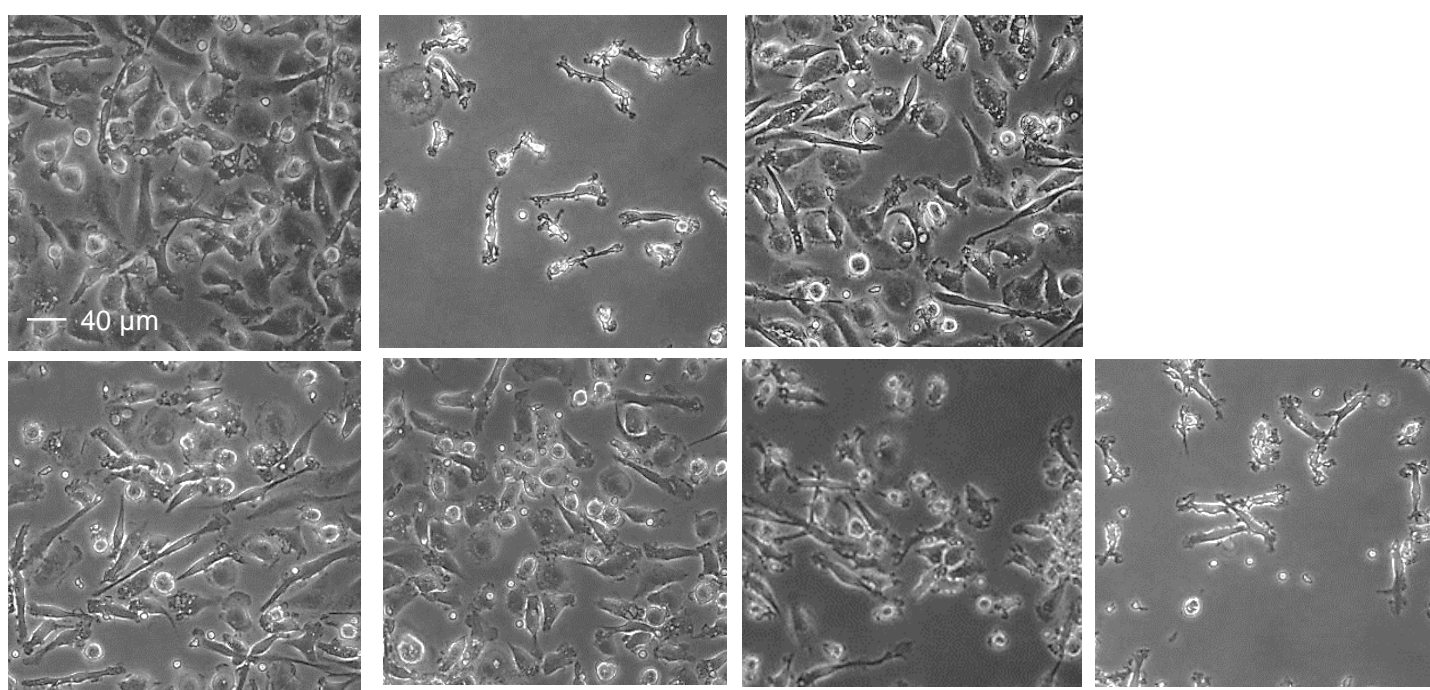

0.05

0.1

0.2

1

NTD $(\mu \mathrm{M})+$ CSF1 (72h)

B
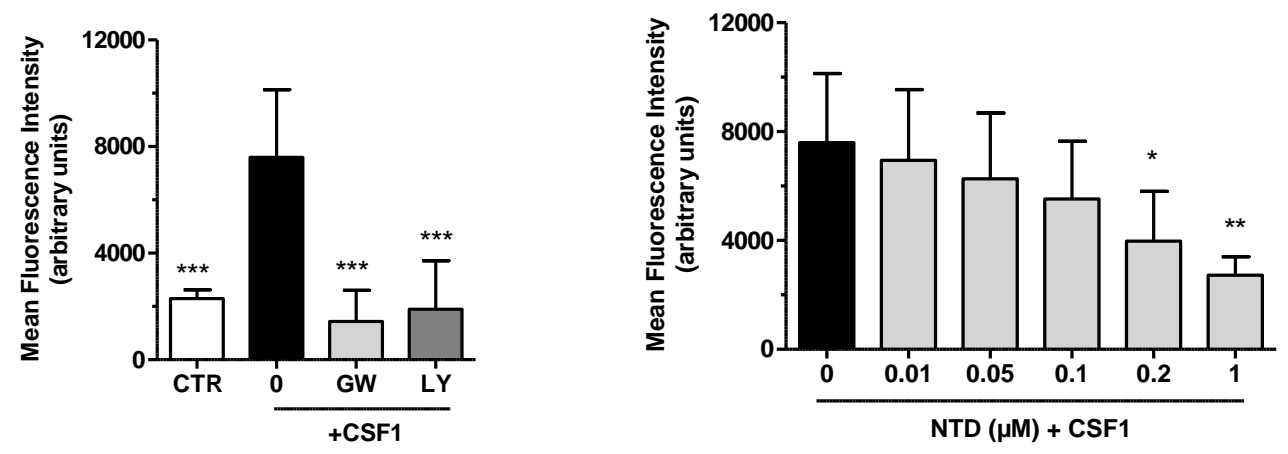

C
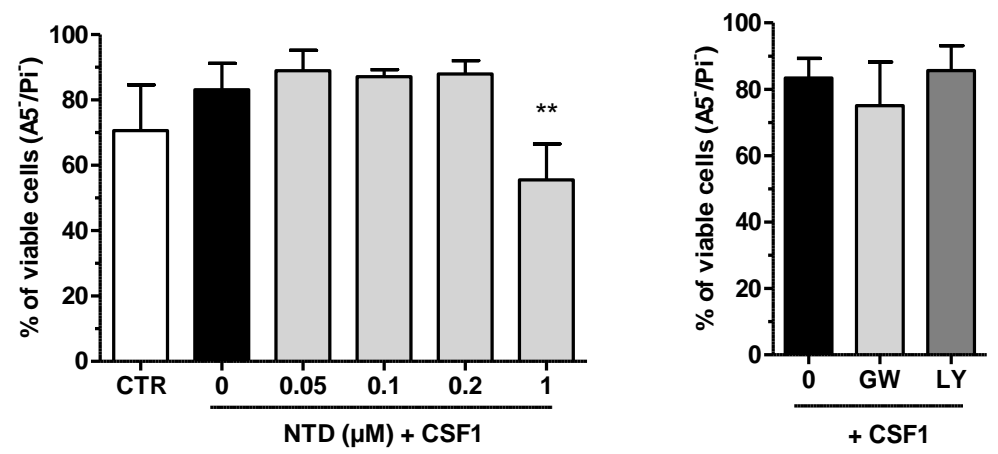
A
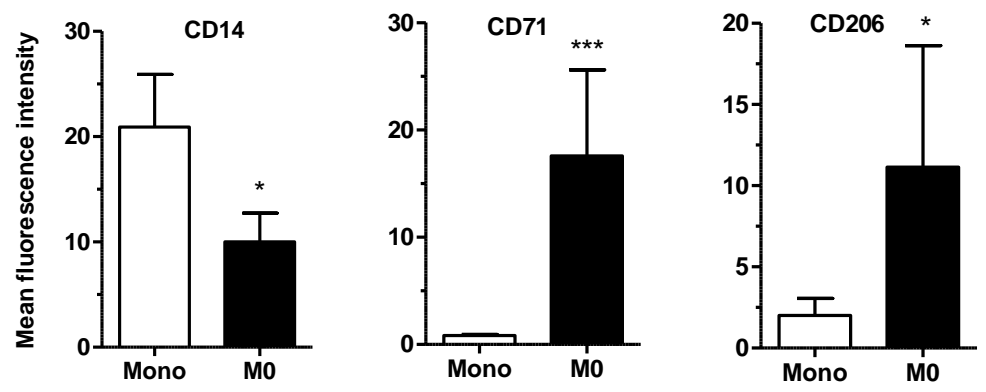

B
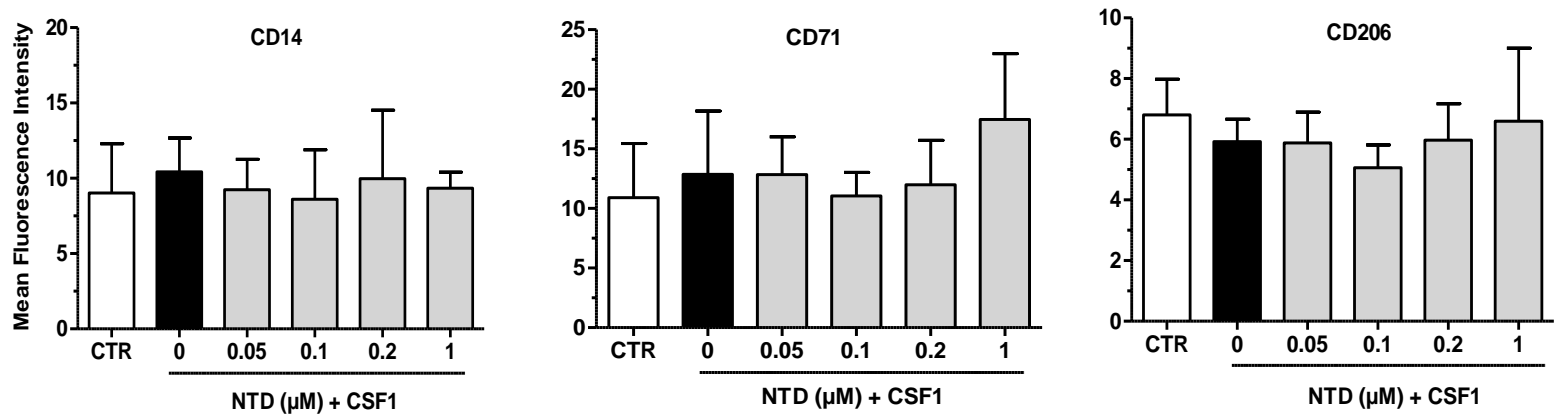

C
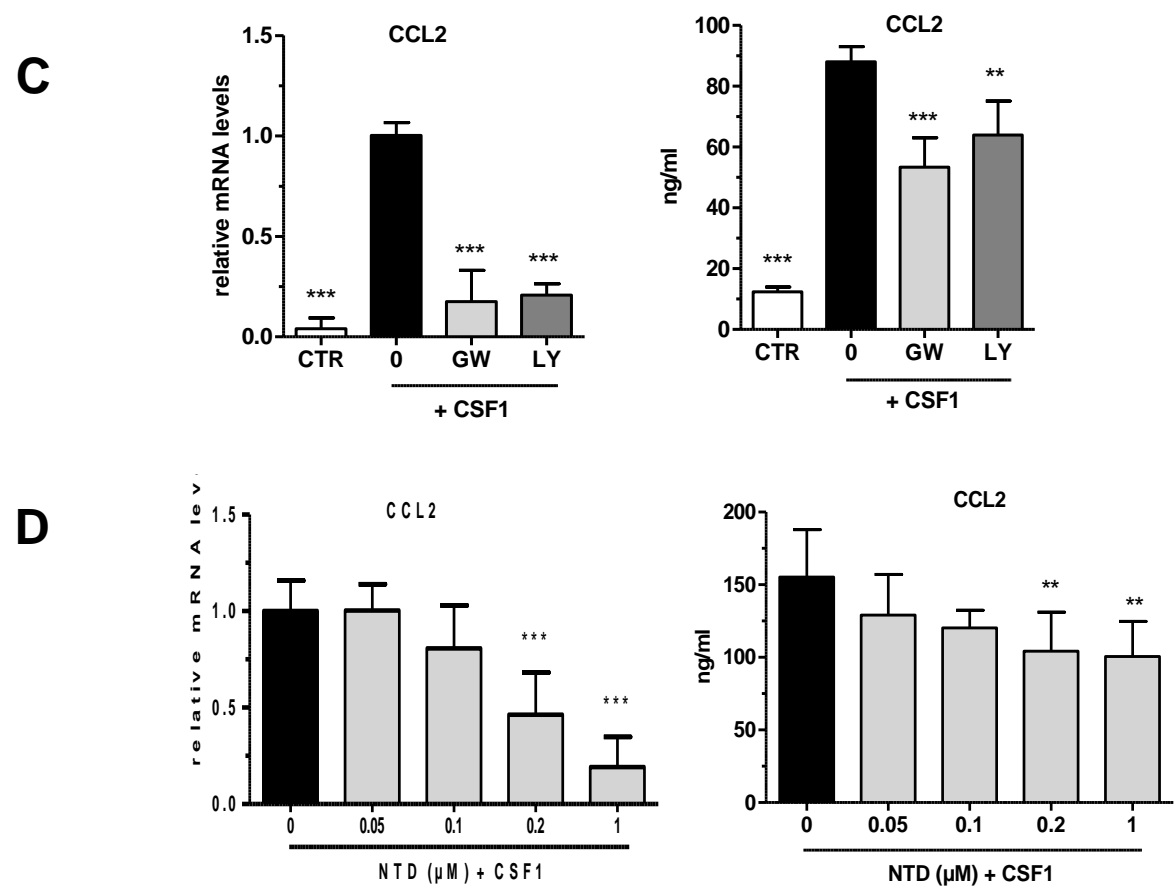
A
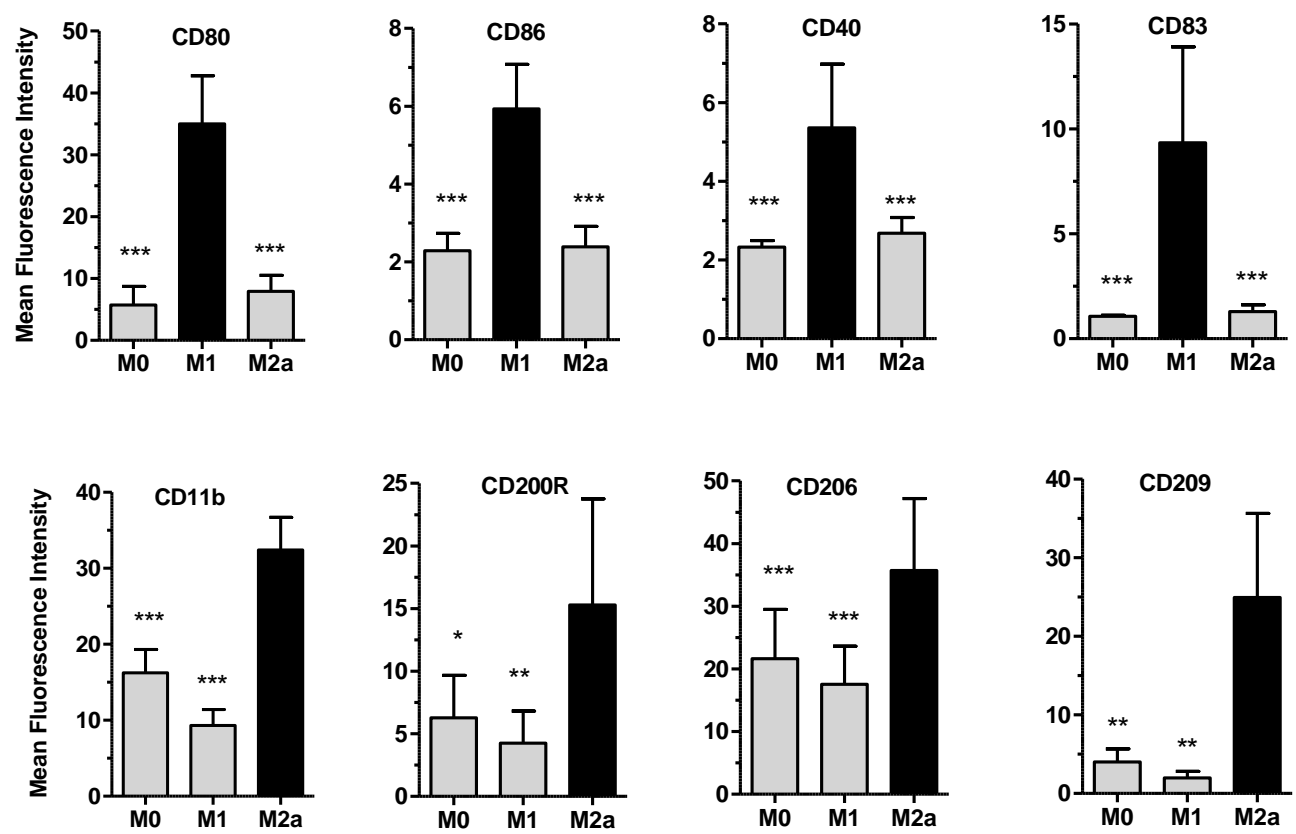

B
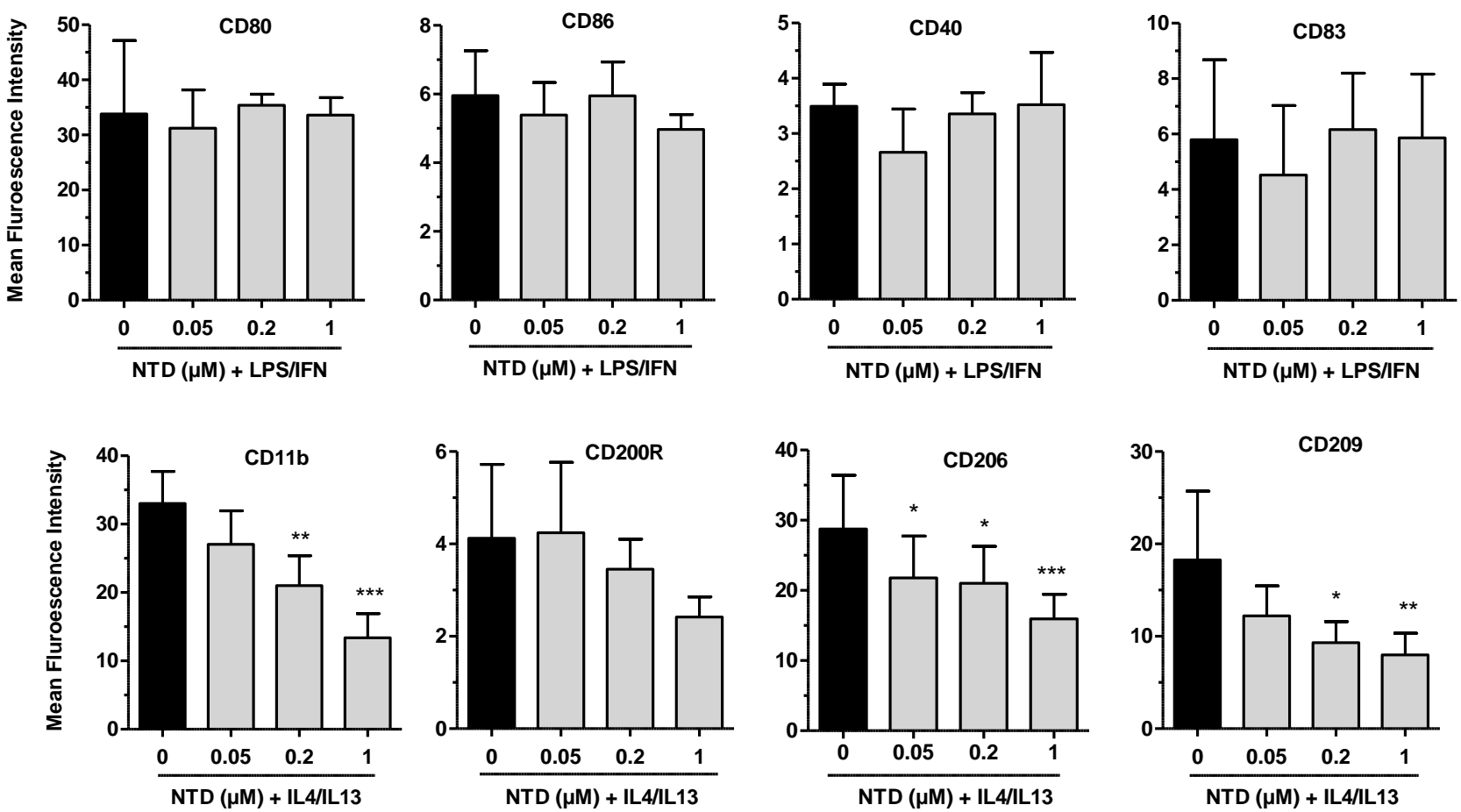

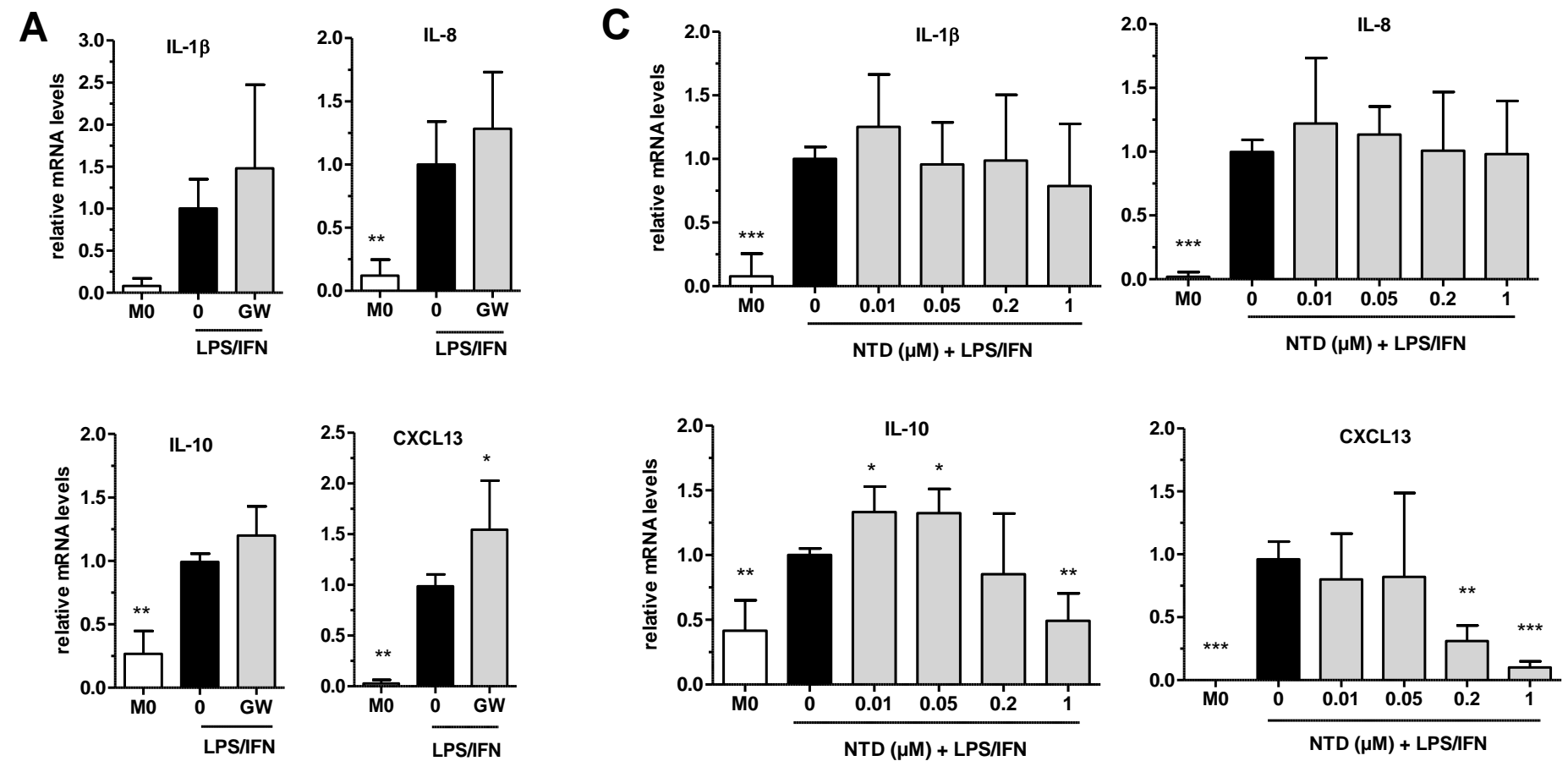

B
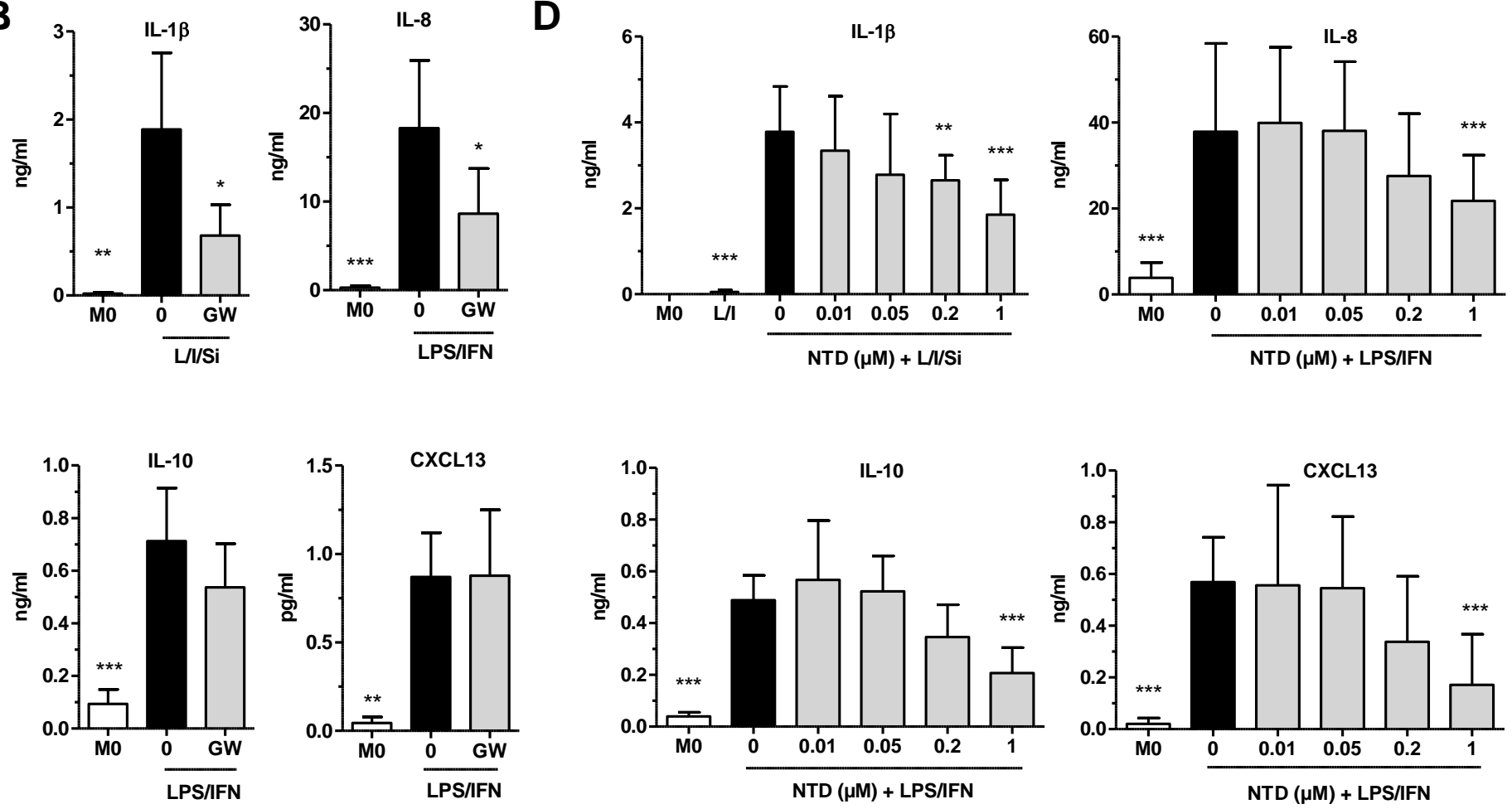
A
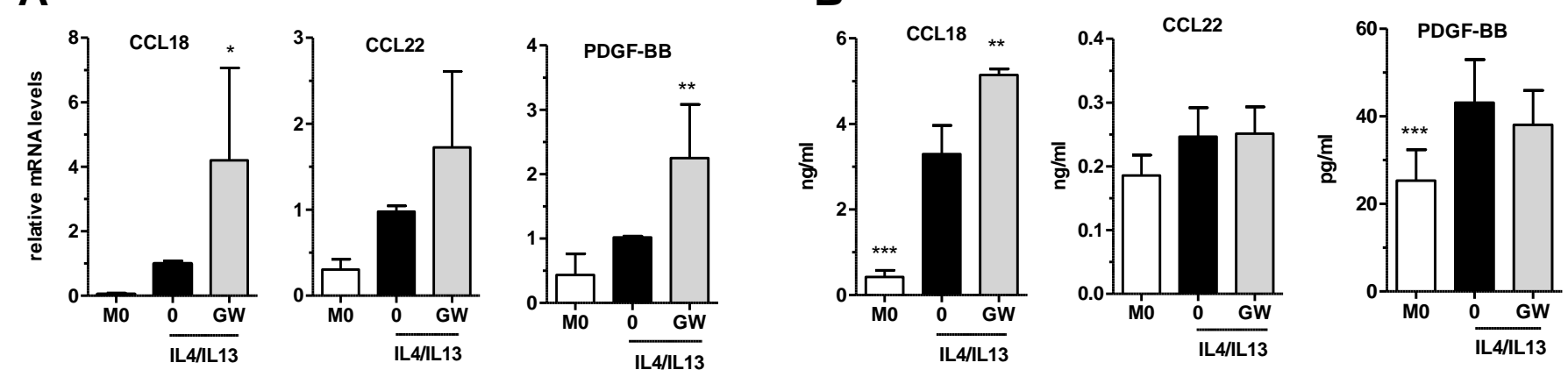

C

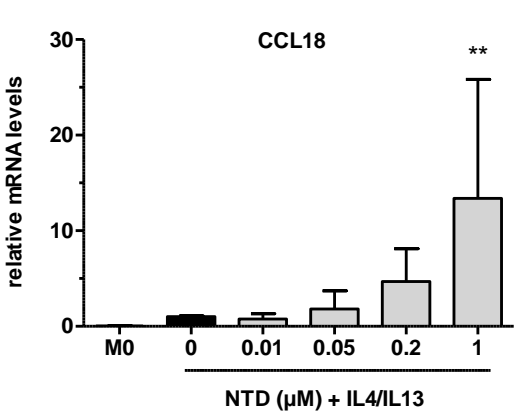

D

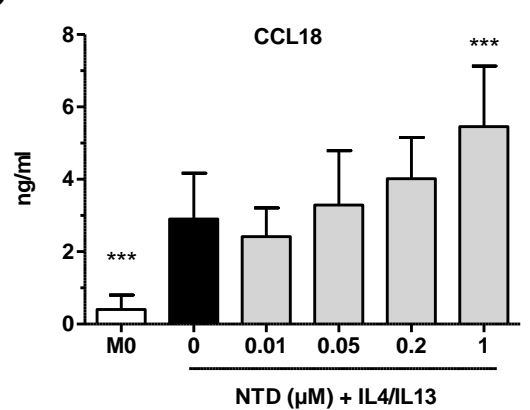

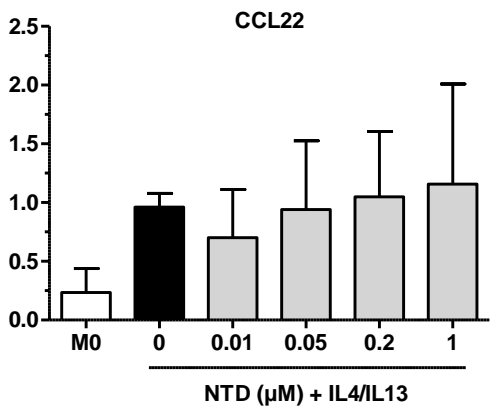
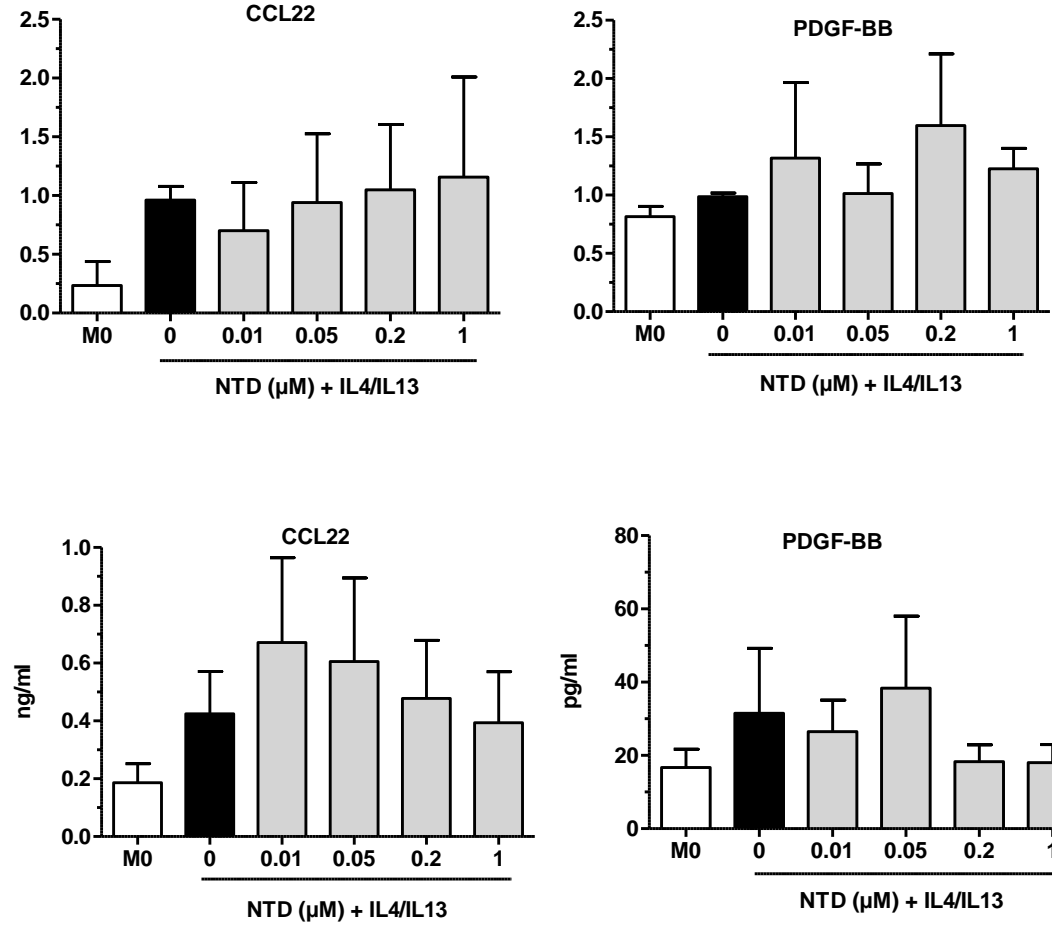

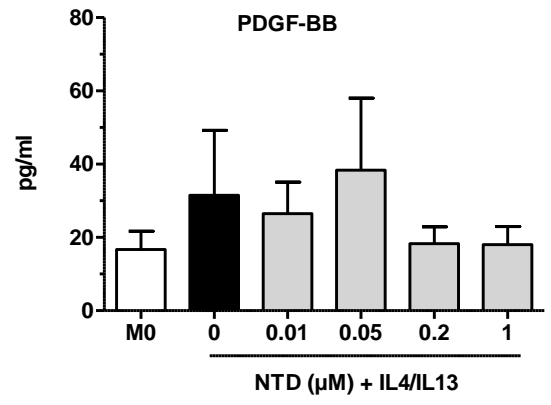




\section{Bellamri et al.}

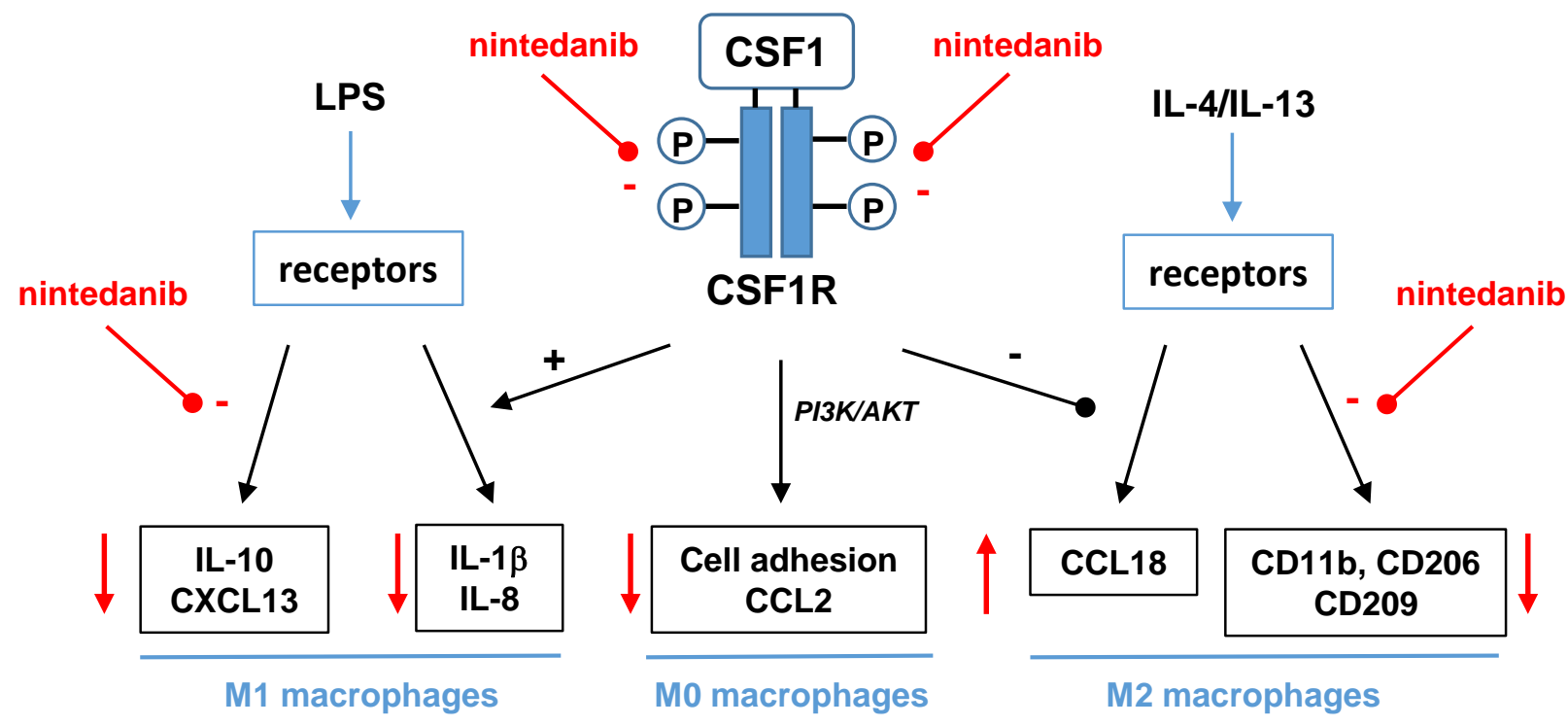

graphical abstract 